Portland State University

PDXScholar

Fall 12-15-2014

\title{
Elaborating Patient Agency in Breast-Cancer Care: A Grounded Theoretical Analysis of Patients Asserting Treatment Preferences
}

Rachel Sofia Erdman

Portland State University

Follow this and additional works at: https://pdxscholar.library.pdx.edu/open_access_etds

Part of the Health Communication Commons

Let us know how access to this document benefits you.

Recommended Citation

Erdman, Rachel Sofia, "Elaborating Patient Agency in Breast-Cancer Care: A Grounded Theoretical Analysis of Patients Asserting Treatment Preferences" (2014). Dissertations and Theses. Paper 2110. https://doi.org/10.15760/etd.2108

This Thesis is brought to you for free and open access. It has been accepted for inclusion in Dissertations and Theses by an authorized administrator of PDXScholar. Please contact us if we can make this document more accessible: pdxscholar@pdx.edu. 
Elaborating Patient Agency in Breast-Cancer Care:

A Grounded Theoretical Analysis of Patients Asserting Treatment Preferences

\author{
by \\ Rachel Sofia Erdman
}

A thesis submitted in partial fulfillment of the requirements for the degree of

\author{
Master of Science \\ in \\ Communication
}

Thesis Committee:

Jeffrey Robinson, Chair

Lauren Frank

Hyeyoung Woo

Portland State University

2014 


\begin{abstract}
Successful physician-patient communication is increasingly being acknowledged as a vital aspect of healthcare today. Research in the field has not examined all aspects of patient-centered care and the aspects that have been studies have not been grounded in actual patient action. The research done in the field has largely been studied quantitatively. The present thesis research attempts to contribute to the gap in the field of physician-patient communication by qualitatively examining patient assertiveness. This thesis examines conversations between women in Portland, Oregon recently diagnosed with breast cancer talking to their surgeons about their diagnoses and treatment options. Using grounded qualitative theoretical analysis, this thesis uncovered five major themes of patient assertiveness in breast cancer care.
\end{abstract}




\section{Table of Contents}

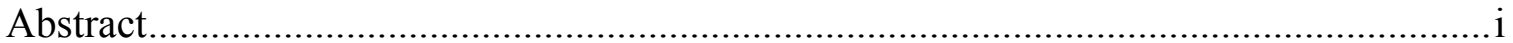

Chapter 1: Introduction \& Review of Literature ...................................................... 4

Motivating this thesis from a qualitative epistemology ....................................... 5

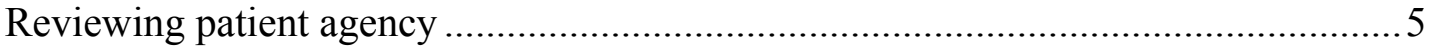

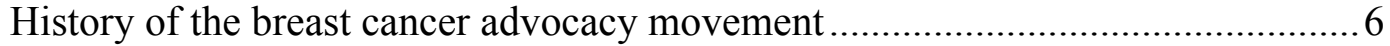

A shift from paternalistic to patient-centered medicine ........................................6

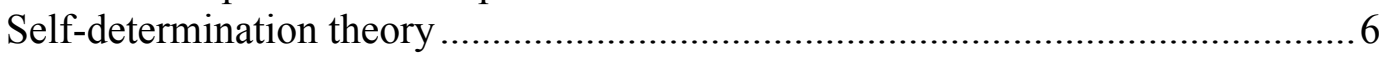

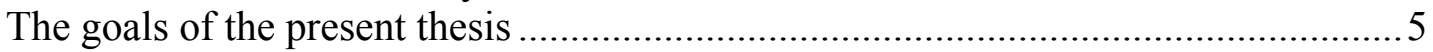

Chapter 2: Data \& Method ......................................................................................... 1

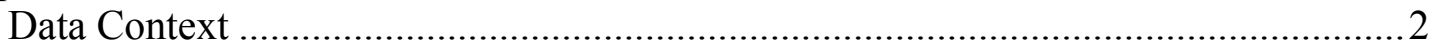

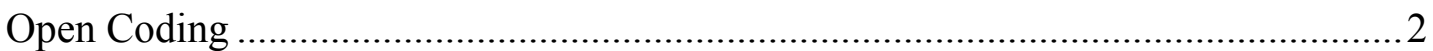

Saturation ..................................................................................................... 2

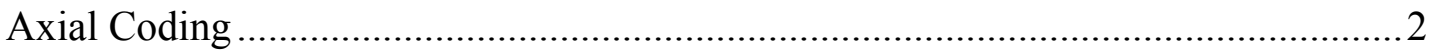

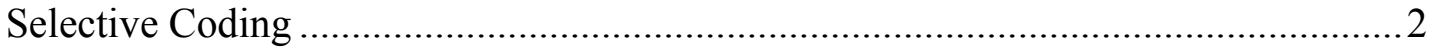

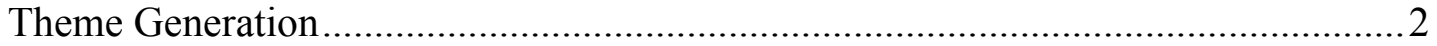

Interactional Positing of Units and Themes ..................................................... 2

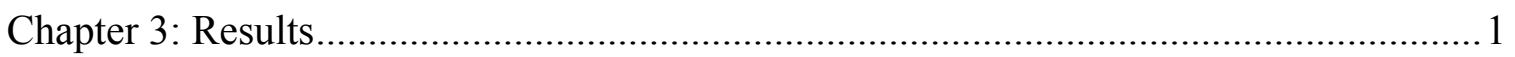

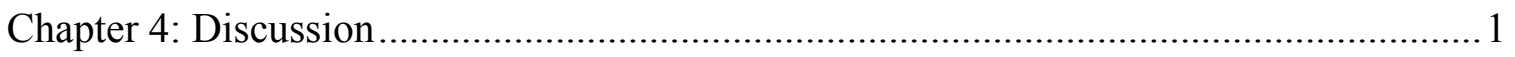

Asserting a Preference for Surgical Option ......................................................... 2

Asserting a Preference - Scheduling Surgery ASAP ....................................... 2

Asserting a Preference for Reconstructive Surgery ............................................... 2

Summarizing Recommendation to Surgeons ....................................................... 2

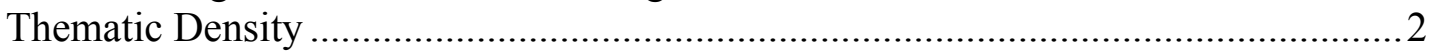

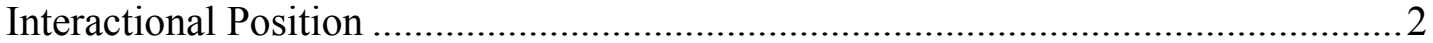

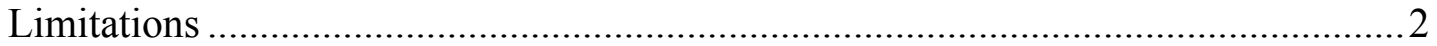

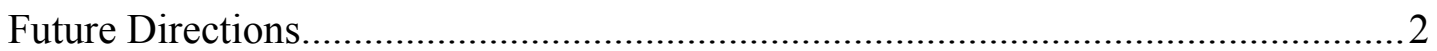

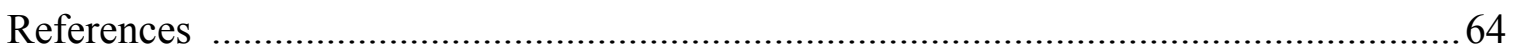




\section{Chapter 1: Introduction \& Review of Literature}

Breast cancer has taken a physiological, physical, and mental toll on women in U.S. society (Siegel, Naishadham, \& Jemal, 2013; Venetis, Robinson, \& Kearny, 2013). Compared to all other cancers, women are more likely to be diagnosed with breast cancer before the age of 60 (Braun, 2003; Bruera, Willey, Palmer, \& Rosales, 2002; Siegel,et al., 2013). In 2013, breast cancer accounted for $29 \%$ of all new cancer cases among women. Furthermore, in 2013, breast cancer was one of the top three cancers diagnosed in women that proved fatal. In 2009, for women between the ages of 30 and 59, breast cancer was the leading cause of death. Largely due to early detection and treatment innovations, these death rates have begun to decline. However, while incidence rates for all other leading cancers are stable, those of breast cancer are not (Siegel et al., 2013).

Alongside the threat to mortality and the multiple physiological consequences of breast cancer (e.g. side effects from treatments, such as lymphedema from lymph-node dissection surgery and fatigue from radiation and chemotherapy), the diagnosis of breast cancer negatively affects multiple aspects of patients' quality of life (Hack, Degner, \& Dyck, 1994; Wells et al., 2012). One key example is that the diagnosis of breast cancer is associated with patients' despair and hopelessness (Robinson, Hoover, Venetis, Kearney, \& Street, 2012). Hopelessness is defined as the belief that "one does not have control over the consequences of one's life ... and the expectation that future events will be negative" (Gidron, Magden, \& Ariad, 2001, p. 289). Research has indicated an association between hopelessness and greater disease progression and earlier death (Everson et al., 1996). Hopelessness has also been found to be significantly associated with the prediction of cancer onset and progression (Gidron et al. 2001). Among female 
breast-cancer patients, cancer-free recurrence and higher survival rates have been found among women who reacted positively or hopefully to their cancer diagnosis (Morris, Pettingale \& Haybittle, 1992).

The good news regarding breast-cancer-patients' hopelessness is that it can be reduced and, relevant to the present thesis, done through methods over which patients have (in principle, at least) complete control. Research has suggested that particular practices of patients' communication with surgeons during treatment-decision making consultations can indirectly reduce patients' levels of hopelessness through increasing their satisfaction with surgeons (Robinson et al., 2012). Specifically, Robinson et al. (2012) demonstrated that instantiations of patients' agency, in the form of patients explicitly asserting their treatment preferences, can indirectly reduce their hopelessness.

Working with Robinson et al.'s (2012) data set, the present thesis is a secondary, qualitative examination of the communicative instantiation of one aspect of breast-cancer patients' agency, patients' explicit assertions of their treatment preferences. This initial chapter is organized as follows. First, it reviews the qualitative epistemology that motivates this thesis. Second, while this thesis is not a theory-based effort to predict health outcomes, it nonetheless contributes to theory development by further refining and specifying the theoretical concept of patient agency. As such, this chapter reviews the concept of patient agency from the perspective of a qualitative epistemology, from the perspective of the breast-cancer advocacy movement, from the perspective of medical education, and finally from self-determination theory (Deci \& Ryan, 1985). To conclude, this chapter articulates and justifies the goals of the present thesis. 


\section{Motivating this thesis from a qualitative epistemology}

According to Blumer (1969), a primary goal of 'traditional' quantitative research is prediction and control, with the assumption that some independent variable ' $\mathrm{X}$ ' (e.g., patient agency) causally affects some dependent variable ' $Y$ ' (e.g., satisfaction). However, Blumer (1969) argued that this assumption is only valid if participants, for example, research subjects, orient to, or understand, the independent variable ' $\mathrm{X}$ ' in the ways stipulated by researchers/theorists. Put differently: Are researchers' operationalizations of variable ' $\mathrm{X}$ ' ecologically valid? While quantitative researchers sometimes do strive to achieve such ecological validity (e.g., through pilot testing, etc.), this is not always the case. Blumer (1969) argued that such ecological validity needs to be proven through systematic explication, rather than being assumed by researchers, and that these processes are the purview of qualitative research. Thus, a fundamental part of qualitative inquiry involves investigating what a given theoretical concept ' $\mathrm{X}$ ' means for the members being studied (e.g., breast-cancer patients), and asks how do members understand ' $\mathrm{X}$ ' as a theoretical concept (e.g., How do breast-cancer patients understand what it means to communicatively instantiate their 'agency'?).

This study is guided by a qualitative epistemology and ontology (Silverman, 2011), and specifically a symbolic-interactionist approach (Blumer, 1969). Blumer (1969) identified two important principles of qualitative epistemology. The first principle is that "human beings act toward things on the basis of the meanings that the things have for them” (p. 2). 'Things' range from objects to other people. The second premise is that 
the meanings people use to navigate their social worlds are largely built through social interaction.

In the context of this thesis, 'members' will be patients, and the concept being studied will be 'patient agency' generally, and specifically 'patients' assertions of treatment preferences.' This thesis utilizes grounded-theoretical methods (which are described further below in the Data/Methods section) to explicate the ways that members understand the act of asserting treatment preferences in and through interaction.

\section{Reviewing Patient Agency}

The present subsection reviews the concept of patient agency, first from the perspective of the breast-cancer advocacy movement, then from the perspective of medical education, and finally from self-determination theory.

History of the breast-cancer advocacy movement. Until the late 1900's, dialogue between physicians and their patients about breast cancer was minimal. The outspoken courage and the promotion of the articulate voices of powerful female public figures - such as Betty Ford in 1974 and Nancy Reagan in 1980 - drew public attention to the psychological, emotional, and physiological dimensions of the breast-cancer experience. These personal accounts, which worked their way into public awareness, normalized and humanized the entire breast-cancer experience. For the first time, women were encouraged to open up about the obstacles they and their family members faced (Brown, Butow, Boyer, \& Tattersall, 1999; Deci \& Ryan, 1985; Pelletier, Tuson, \& Haggad 1997; Ryan, \& Conell,1989; Ryan, Plant, \& O'Malley, 1995).

Public health advocates followed this lead. In the early 1980's, screening guidelines were established and regular mammograms and breast self-examinations 
(BSEs) were encouraged. With this information, it became much more possible for the average woman and her family to understand the consequences of a breast-cancer diagnosis, both personally and collectively. Women began to actively participate and engage in conversations with their physicians when diagnosed. The importance of breast self-examinations and mammograms was promoted through the media (Braun, 2003; Miller, Miller, \& Joanne, 2006).

As public advocacy groups spread around the world, and as organizations like Komen Race for the Cure encouraged patient participation and advocacy, patients began to talk about the role they wanted to play in their healthcare (Braun, 2003). Susan Komen's sister launched the Susan G. Komen Organization after Susan lost a long and hard battle with breast cancer. Betty Ford's public and successful battle with breast cancer encouraged Susan to keep fighting her disease even after her trusted, local, family doctor had told her that "he could cure her." After her lumpectomy, Susan's surgeon told her family to “...relax, we got it all. I believe she's cured.” Her now-educated family knows this assessment was completely inaccurate ("Susan G. Komen’s Story,” n.d)

In the early 1980 's, as individual patient education became a more common practice in certain demographic populations, expanded reports of personal experiences with breast cancer emerged (Vogel, Helmes, \& Hasenburg, 2008). Books, articles, and literature generally written by and for women appeared. This evolving literature functioned as mentorship, guiding women through their breast cancer journeys and instructing them to advocate for themselves during the process. For instance, Royal (2011) gave readers practical, step-by-step and stage-by-stage instructions about how to actively advocate for themselves by asking readers to do things like "educate yourself 
about your illness, make a list of questions before you go to your appointment, and schedule your appointment first thing in the morning or be the first patient they see after lunch; avoid weekends and holidays when possible" (Royal, 2011, p. 89).

As personal patient advocacy became publicly normalized, patients made it known that they wanted to be informed and active players in the decision-making process at all crucial stages of their diagnosis (Braun, 2003; Fraenkel \& McGraw, 2007). Studies relating to the information needs of breast-cancer patients show that patients are most interested in treatment-related information, cancer-specific information, and rehabilitation information (Vogel et al., 2008). The literature on this topic consistently states that patient advocacy is essential in patient information seeking. Because of the vast amount of information on cancer diagnosis that is now available, it can be difficult for physicians to tailor information to each individual patient. In order to achieve better results and health outcomes, patients need to be involved in their healthcare in order for physicians to better formulate treatment plans that are right for their patients (Schofield \& Butow, 2004; Vogel et al., 2008).

Today, successful communication in healthcare is not only crucial but also expected for successful physician-patient interactions and relationships. Patient participation in healthcare has robustly become part of the mainstream model of medicine. The expectation for patients to participate in the decision making process is becoming increasingly more popular. The World Health Organization describes patient involvement as "a social, economic, and technical necessity" (Guadagnoli \& Ward, 1998, p. 329). Additionally, 18 states in the US have laws that require physicians to inform 
women about treatment options for breast cancer (Nattinger, Hoffmann, Shapiro, Gottlieb, \& Goodwin, 1996; Nayfield, Bongiovanni, Alciati, Fisher, \& Bergner, 1994).

Occasionally, progressive movements in healthcare education focus minimally on healthy physician communication skills. Even more rare, but equally important, is patient education in agency and advocacy in a healthcare setting. Fairly extensive research has been devoted to patient question asking and patient-centered care (Roter, 1977; Street 2001). Qualitative research, as proposed in this thesis, which examines what advocacy means 'on the ground' for breast cancer patients, should provide additional insight into how patients can effectively advocate for themselves.

A shift from paternalistic to patient-centered medicine. Physicians have, historically, dominated and controlled the limited amount of time they have with patients. What physicians perceive as being important to discuss is often the only thing that is discussed. This has been identified as a paternalistic style (Buchanan, 1978; McKinstry, 1992). Medical paternalism is a philosophy that implies that healthcare decisions are best left to physicians. The paternalistic model promotes interacting with patients as a father would with a child, and limiting the patients' autonomy with the intent of doing them good. Physicians who 'know best' listen to the patients' points of view but then enforce strict guidelines. The word paternalism comes from the Latin word pater (i.e., father) and includes an attitude of superiority. In the medical context this refers to the withholding of relevant information, or providing information in a limited way so that patients will be 'better off.' There are varying degrees of paternalism, called 'soft' or 'hard' paternalism, as well as 'moral' and 'legal' paternalism, but they all result in limiting patients' healthcare autonomy (Buchanan, 1978; Dworkin, 2005; McKinstry, 1992). 
In contrast, patients prefer a mixed-method communicative approach where patients are in charge, physicians contribute thoughts and ideas, and physicians are honest with patients regarding medical processes (Beisecker \& Beisecker, 1990; Brown et al.1999; Hack, Degner, \& Parker, 2005). A shared decision-making approach comes into play here. Based on a meta-analysis, Guadagnoli and Ward (1998) showed that, while patients do not want to be in complete control of their healthcare, they do want to play an active role in it. Patients want to be able to make final decisions regarding cancertreatment options, and patients also want to be completely informed regarding all the risks and benefits of all options regarding treatment (Hack et al. 2005). Over the past three decades, healthcare has moved away from the paternalistic view of medicine. Now that patients are capable of becoming participatory decision-makers, they are no longer passive recipients of medical care, but rather active participants.

In line with this shift, treatment decision making has focused less on physicians being in control and more on a partnership between healthcare professionals and patients (Bensing, 2000; Charles, Whelan, \& Gafni, 1999; Epstein \& Street, 2007). Instead of physicians being the only one in power, and the only one with information, healthcare has been pressing more toward patient-centered approaches and building relationships through shared decision-making (SDM). SDM, conceptualizes patient autonomy as a basic and fundamental aspect of patient participation. SDM represents an approach that leads patients and physicians through the decision making process together. Both parties arrive at decisions that are deemed mutually agreeable. Most research investigating the types of participation that patients prefer has revealed that a shared decision making approach is what best suits them (Bruera et al., 2002; Epstein \& Street, 2007; Guadagnoli 
\& Ward, 1998; Joosten et al., 2008; Whitney, 2003). This means that investigating the way patients advocate for themselves and are a part of their treatment process is worthwhile. Furthermore, patients' preferred participation behaviors vary by context; studying individual contexts of patient participation can help researchers and physicians alike gain a better understanding of what works best in specific healthcare settings.

Patients who are more active in their healthcare are able to elicit information not spontaneously offered by physicians, and actively determine the topics of discussion, the length of the visit, and the amount of information provided (Miller, 2006). Research measuring how involved patients want to be in their healthcare varies from case to case (Guadagnoli \& Ward, 1998; Vogel et al., 2008). Several other motivators for patient participation have been identified through research. Patients participated more when they were interested in having control over their body and life. Other patients participated less because they had vested faith in medical expertise (Beisecker \& Beisecker, 1990; Hack et al. 1994).

Decision-making outcomes demonstrate the benefits of patient participation. When patients are involved in their healthcare, they have more control over the decisions they make, which leads to more effective healthcare. Higher levels of patient participation result in patients being more motivated to follow treatment plans correctly and benefit patients' overall health outcomes (Vogel, 2008). Some research suggests that patients who are more involved in their healthcare decision making experience reduced pain and anxiety, quicker recovery, and increased compliance (Guadagnoli \& Ward, 1998). Educating patients on how to be their own best advocate and how to be involved in their own healthcare proved to be effective for varying populations (Brashers, Hass, \& 
Neidig, 1999; Cortes, Mulvaney-Day, Fortuna, Reinfeld, \& Alegria, 2009; Guadagnoli \& Ward, 1998). More research in patient advocacy will contribute to a greater understanding of how advocacy influences these situations and, most importantly, how advocacy influences decision-making for patients. In order to understand patients are motivated to make decisions and advocate for themselves, it is important to review selfdetermination theory.

Self-determination theory. Humans are inherently active, dynamic organisms with natural tendencies that lead them toward growth, change, and evolution. When people are given the opportunity to behave in ways that allow them to accomplish tasks at their highest potential, they are motivated, responsive, and responsible. They are able to master new skills, seek out interests outside of their immediate surroundings, learn new facts, communicate productively with others, and integrate learning into a sense of self (Ryan \& Deci, 2000). The creation of self-determination theory (SDT) in 1980 spawned an interest into the investigation of motivation. Researchers have demonstrated a vested interest in exploring what drives some people toward the achievement of success and content. For example, why are some people able to express their emotions seamlessly while others are aggressive and angry? Self-determination theory offers insight into intrinsic and extrinsic motivation and its relationship to human cognitive and social development. SDT helps us understand the social and cultural factors that affect the initiative we may or may not take concerning personal motivation, volition, and the quality of our performance. Self-determination theory provides a foundation for the exploration of the factors that shape patient agency. 
Self-determination theory posits that autonomy, competence, and relatedness are the three key determinants of motivation and engagement. According to SDT, all three of these components are necessary for human engagement to occur and thrive. Autonomy, competence, and relatedness provide insight into how these determinants can be used to predict patient agency and, in particular, how these three determinants can lead to patients advocating for themselves during physician-patient interactions (Deci \& Ryan, 2002).

Patient self-advocacy occurs when patients are motivated, of their own volition, to speak-up for themselves. According to SDT, all humans have an innate need to be autonomous; this need motivates humans to engage with others. Human actions stem from personal interests and engagement with situations. People take action because of their desires and preferences; this defines autonomy (Deci \& Ryan, 1985). This does not mean that patients want to make decisions without the involvement of others, namely physicians. It is suggested that autonomously motivated patients advocate for themselves without being controlled by others (Epstein \& Street, 2011).

In order for autonomy to be manifested, competence must be present to some degree. Competence involves a level of control regarding patient agency. Patients feel more competent when they feel intrinsically effective (Deci \& Ryan, 2002). In the context of this proposal, this also means that patients must have the appropriate amount of knowledge and skill in order to be confident enough to express their autonomy when engaging with their physician and in order to advocate for themselves. Patients who feel relatedness, from their external environment and physicians, are more likely to feel competent and autonomous in engagement. Patients need to feel that they are not alone in 
their journey. In order for patient agency and engagement to occur, there needs to be a feeling of connectedness and belonging with others like them and with the people around them (Deci \& Ryan, 2002, 1985; Epstein \& Street, 2011; Street \& Millay, 2001).

Studies examining the contributions of self-determination theory in healthcare show that, when healthcare providers support patient autonomy, patients are more motivated to behave in healthier ways (Brown et al., 1999; Deci \& Ryan, 1985; Pelletier et al., 1997; Ryan \& Connell, 1989; Ryan et al., 1995; Williams \& Deci, 1998). Providers supported patient autonomy by listening carefully to patients' perspectives, encouraging questions, providing relevant information, offering choices about treatment regimes, supporting patients' initiatives, and minimizing control (Williams, Deci, \& Ryan, 1998; Williams \& Deci, 1998; Williams et al. 1991). It is important to note that the literature does not recommend that autonomy support be employed in ways such that healthcare providers are detached, or in ways that allow patients to make medical decisions without the appropriate information or advice from healthcare providers. Instead, it defines autonomy support as actively engaging with patients in a supportive style that reflects an understanding of their feelings and perspectives and, when appropriate, offering advice without pressures or demand (Bruera et al., 2002; Deber, Urowitz, \& Sharpe, 2007; Joosten et al., 2008; Kraetschmer et al., 2004; Vogel et al., 2008; Whitney, 2003). Survey-based literature suggests that patients' 'autonomous' behaviors include being involved in discussions of their healthcare, and voicing their feelings emotions, perspectives, agendas, and choices.

For example, Williams, Niemiec, Patrick, Ryan and Deci (2009) found that inducing heavily addicted, long-term smokers to be more autonomous increased their 
commitment to smoking cessation. Williams, Cox, Kouides, and Deci (1999) found that increasing patients' autonomy was significantly associated with patients reducing their high levels of smoking and reporting a decreased likelihood of smoking in the future. In a study of patients with diabetes, Williams, Freedman, and Deci (1998) found that patients who reported that providers supported patients' autonomy (vs. providers who did not) demonstrated increased glucose regulation. Patients felt that healthcare providers encouraged autonomy when they acknowledged patients' emotions and put minimal pressure on patients to behave in specific ways or make specific choices (Williams et al., 1998).

Results based on self-determination theory have been replicated by observational studies that code actual physician-patient interaction. A systematic review of these findings (Epstein \& Street, 2011) showed that patients who communicatively embody increased levels of patient agency/assertiveness are more satisfied with their care, receive more patient-centered care from physicians, are more committed to treatment regimens, and have stronger senses of self-control over their own health (see also Street, 2001). Female patients experienced less regret and greater satisfaction when they engaged in a more active decision-making style, and when they achieved their preferred decisionmaking style (Hack, Degner, Watson \& Sinha ,2005). Street (2005) found that patient participation increased when physicians used partnership-building and supportive talk (e.g., reassurance, encouragement).

In sum, self-determination theory has been used to predict patients' engagement with their physicians. Tests of self-determination theory have been premised on specific measures of 'patient engagement' (see below). These measures have operationalized 
'patient engagement' in ways that have not adequately considered patients' actual behavior, at least in the context of their treatment decision making surrounding breast cancer. As Blumer (1969) argued (see above), a valid conceptualization of 'patient engagement' must be developed through an understanding of how patients themselves actually 'engage' in their treatment, which is the goal of the present thesis. Thus, the present thesis is not traditionally motivated by self-determination theory, in the sense of using it to predict and explain behavior. Rather, the present thesis is investigating a concept used by self-determination theory in order to refine it.

\section{The goals of the present thesis}

From the prior review of literature, it is clear that the concept of 'patient agency' is important from the applied perspective of the breast-cancer advocacy movement, from the perspective of medical education, and from the perspective of self-determination theory. All of these perspectives variously point to the concept of 'patient agency' as being positively associated with myriad beneficial health outcomes (Williams, Frankel, Campbell, \& Deci, 2000; Venetis, Robinson, Turkiewiez, \& Allen, 2009). In line with the goals of qualitative research (reviewed above), the present thesis addresses a major gap in the literature, which is an examination of the 'ecological validity' of the concept of patient agency. Specifically, how do patients understand the concept of 'patient agency?' More specifically, what does the process of communicatively instantiating 'patient agency' mean to patients?

Literature examining patient agency and autonomy has not grounded the operationalization of the concept of patient agency/autonomy in actual behavior. For example, in the literature involving self-determination theory, patient agency/autonomy is 
measured by patients' self reports in the form of answers to Likert-type questions, such as "I am free to do whatever I decide to do" as a measure of choicefulness (Street, 1992; McCormack et al., 2011). Even when researchers have coded for patient agency/autonomy in actual interaction, their guiding operationalizations (at least as specified in published code books) have been extremely broad and relatively content free. For instance, Street, Gordon, Edward, and Richard (2005) operationalized patients' assertive utterances as "utterances where the patient interjects his or her beliefs, preferences, and perspective into the consultation" (p. 1315.). Examples given to coders are patients "offering an opinion about health or treatment, making a recommendation, disagreeing with the doctor, making a request, and introducing new topics for discussion.” As Blumer (1969) argued, while it is possible that the aforementioned operationalizations are ecologically valid, this must be verified through qualitative examination of particular contexts of data, which this thesis attempts to do.

The present thesis answers the following qualitative research question: In the context of surgeons discussing diagnoses and treatment options with recently diagnosed, female-breast-cancer patients, what do recently diagnosed breast cancer patients advocate about during consultations with surgeons? Through this qualitative investigation of what patients' understandings of what 'asserting treatment preferences' means to them, patient involvement in medical encounters can be further understood, and a shared decisionmaking model of healthcare can be better explicated. 


\section{Chapter 2: Data and Method}

\section{Data context}

Data used for this research were previously collected by Robinson et al. (2012) for a study conducted in Portland, OR from August 2010 to September 2011. Participants were 147 newly diagnosed, English-fluent women with breast cancer who were consulting with one of nine surgeons prior to surgery to discuss the nature of their cancer and a treatment plan. As reported by Robinson et al. (2012), median time since diagnosis was 7 days, with $56.5 \%$ of cancers estimated to be greater than stage 1 and $93.2 \%$ of patients were experiencing cancer for the first time. Patients were an average of 60.5 years old, a majority being white, non-Hispanic (94.6\%), married (62.8\%), religious (69.4\% attending formal religious services at least weekly), not college educated $(62.2 \%$ with less than a B.A.), with a household income less than $\$ 60,000$ per year $(57 \%)$, who brought at least one companion ( $83.8 \%$ brought a husband, sister, friend, etc.), who were seeing the surgeon for a first opinion (90.1\%), and who had never previously communicated with the surgeon (93.9).

Patients filled out a pre-consultation survey (12 minutes), had their consultation videotaped with a small, battery operated, ceiling mounted, digital camera (research staff were not present), filled out a post-consultation survey (12 minutes), and were finally paid \$20 for their participation. All consultations were transcribed in their entirety and produced 6,251 pages of transcript. All transcripts were reliably coded (see Robinson et al., 2012 for acceptable inter- and intra-coder reliability estimates) in conjunction with videotapes for seven different types of 'patient-centered communication behavior,' of which 7,204 instances were identified. The patient-centered communication behavior 
focused on in this thesis is 'patient asserting treatment preference'. This code was operationalized as "any utterance in which a patient articulated a preference, desire, or opinion regarding any aspect of treatment (e.g., surgery, radiation, or chemotherapy)" (Robinson et al., p. 352). Patients asserted their treatment preferences an average of 8.46 times per visit, and did so in $94 \%$ of all visits. See the section below on 'open coding' for examples of 'patients asserting treatment preference' (see Robinson et al., 2012, for how transcripts were unitized, and for unitization reliability, which was acceptable). Data for the present thesis were 100 visits randomly selected from the larger data base, which yielded 1,083 instances of 'patients asserting treatment preferences.' The analytic decision to select a relatively large number of 100 visits for qualitative inquiry - as opposed to a smaller number, as is sometimes recommended (Silverman, 2011) - was justified by a desire to generate reliable findings regarding a single theoretical concept (i.e., patient agency). The tradeoff, as discussed below, was that less qualitative analysis was performed on each unit of analysis.

\section{Open coding}

After unitizing data (see above), the first analytic step in a grounded-theoretical approach is referred to as 'open coding' (Strauss \& Corbin, 1998). During open coding, the researcher inductively 'labels' each unit, which involves describing it in terms of communicative action (i.e., what the patient is 'doing,' 'meaning,' or 'trying to achieve' with the utterance). For completely new (i.e., previously unanalyzed) data sets, the grounded-theoretical process of open coding is not initially structured or guided by prior conceptualizations of communicative action. However, this was not the case for the present thesis; that is, units had previously and reliably been identified as instances of 
'patients asserting treatment preferences.' In the present thesis, the focal units were 'open coded' only in terms of the specific nature of treatment preferences being conveyed. Note that this does not mean that all units were assumed to be an instance of 'patient asserting treatment preference' and 'forced' into a label. Rather, each unit was initially qualitative assessed for whether or not it was, in fact, an instance of 'patient asserting treatment preference.' In a very few cases units were disqualified and omitted from the analysis. For example, in Extract 1 below, the unit was determined to be an instance of 'patient seeking medical information,' which is a form of patient information seeking, which is another type of 'patient-centered communication' and was omitted from the analysis. These cases represent coding errors in Robinson et al. (2012). In transcripts of all data exemplars, patients are referred to as 'PAT' (in left margins), patients' companions (e.g., sisters, husbands, friends etc.) are referred to as 'CPN,' surgeons are referred to as 'SUR,' and surgical assistants are referred to as 'AST.' In transcripts of all data exemplars, the focal assertive utterance is represented in boldface type and indicated by an arrow (-->) in the left-hand margin.

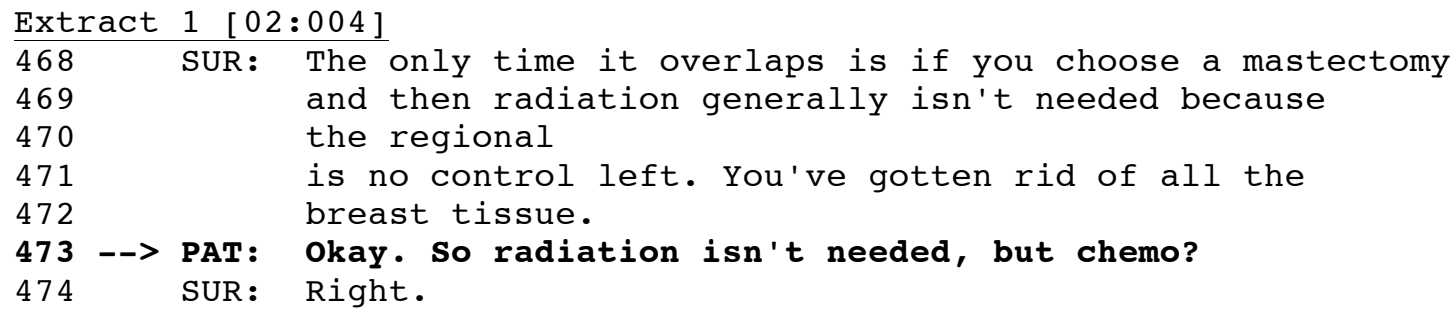

The following six cases are examples of how data were open-coded in terms of 'patient asserting treatment preference.'

In Extract 2, the unit of analysis was the patient's assertion at line 785: "I just want it over." This unit was open-coded as: Patient asserts a desire to have surgery 'over' 
as soon as possible in the face of deciding to undergo chemotherapy first. Here and elsewhere, according to the process of 'open coding' (Strauss \& Corbin, 1998), efforts were made to use patients' own words in describing communicative action, and to make descriptions context dependent.

Extract 2 [Visit:001.047]

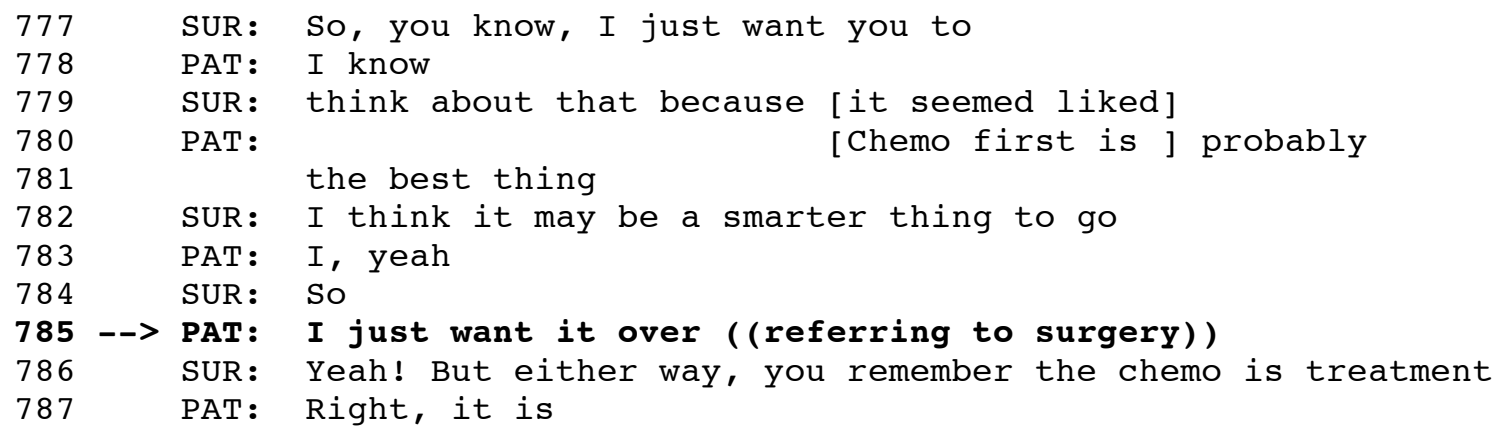

In Extract 3, the unit of analysis was the patient's assertion at line 978: "I want to get it done as soon as possible after talking." This unit was open-coded as: Patient asserts a desire to have surgery 'done' or scheduled 'as soon as possible' after 'talking' with surgeon.

\section{Extract 3 [Visit:001.073]}

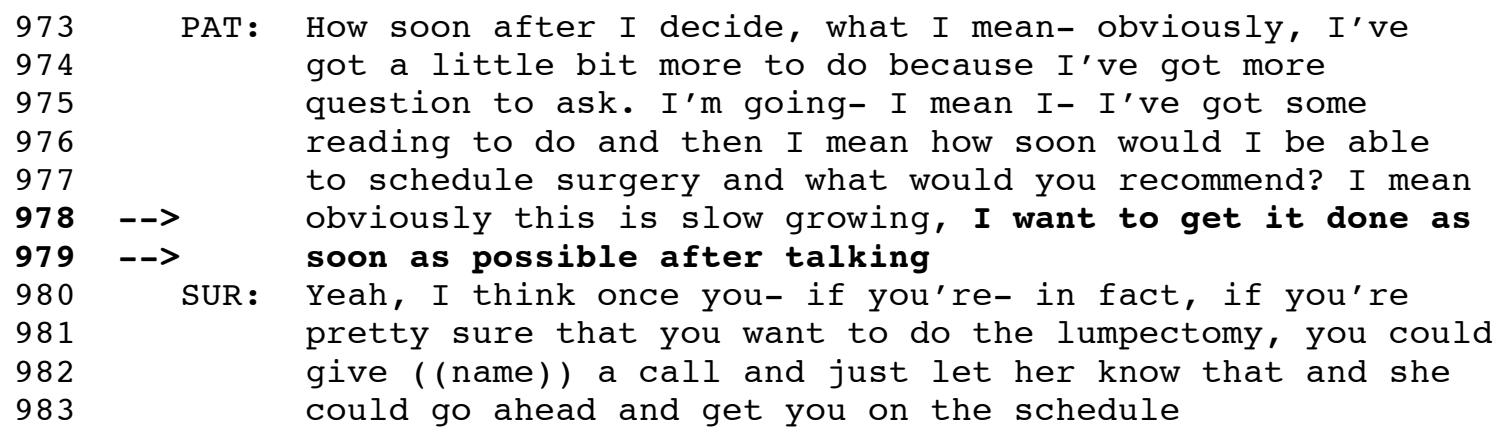

In Extract 4, the unit of analysis was the patient's assertion at lines 1050-1051: “I would prefer to have the surgery back here.” This unit was open-coded as: Patient asserts a preference to have surgery 'here' (i.e., in Portland vs. Florida). 
Extract 4 [Visit:002.058]

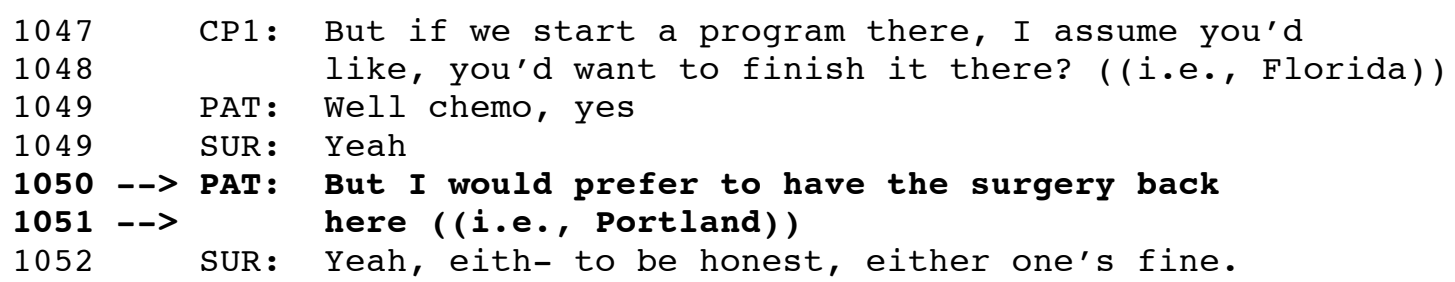

In Extract 5, the unit of analysis was the patient's assertion at line 625:

"Whichever one's closer." This unit was open-coded as: Patient asserts a preference to have surgery at the facility 'closest' to her.

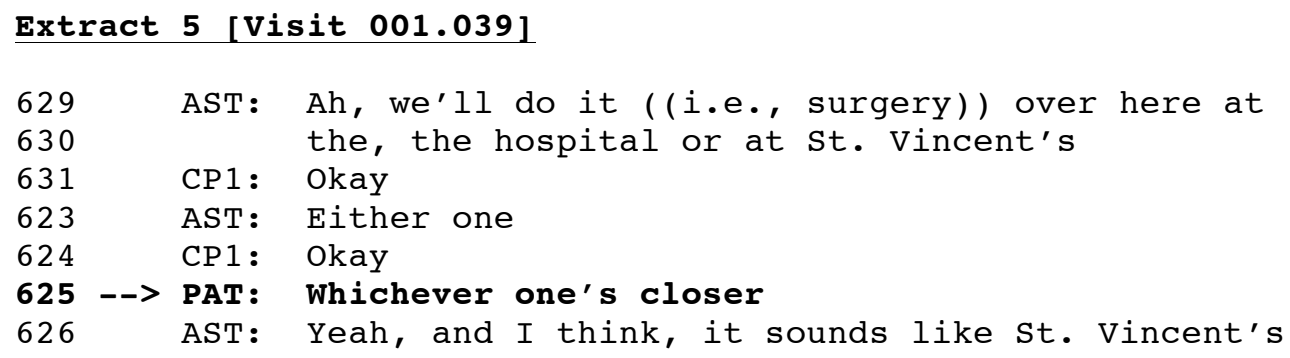

In Extract 6, the unit of analysis was the patient's assertion at line 568:

"Wednesday, probably." This unit was open-coded as: Patient asserts a preference to have her pre-surgical consultation scheduled for 'Wednesday.'

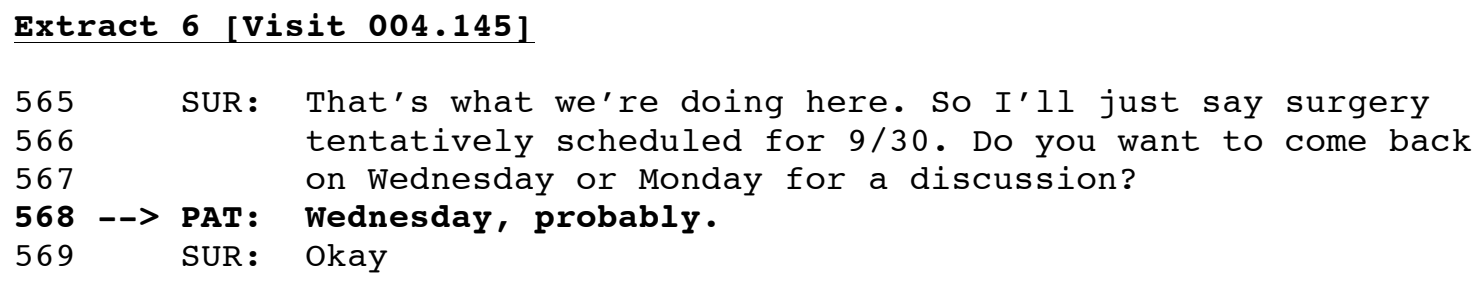

\section{Saturation}

The next step in the qualitative research process is coding the data until it has become saturated. Working from the fact that the communicative constitution of meaning is, while diverse, nonetheless systematic (Strauss \& Corbin, 1998), over the course of 'open coding,' unique labels tend to become less and less frequent. That is, in 
the beginning of 'open coding,' each next unit tends to be given a unique label (as are the six open-code labels represented in extracts 1-6, above), but over time unique labels become more and more infrequent. At some point, researchers arrive at 'saturation,' which is a non-precise term used to characterize the time during open coding when researchers determine that data are no longer generating (enough) new or unique labels. For example, the following two units were coded as essentially having the same opencode label 'patient asserts that she wants a lumpectomy':

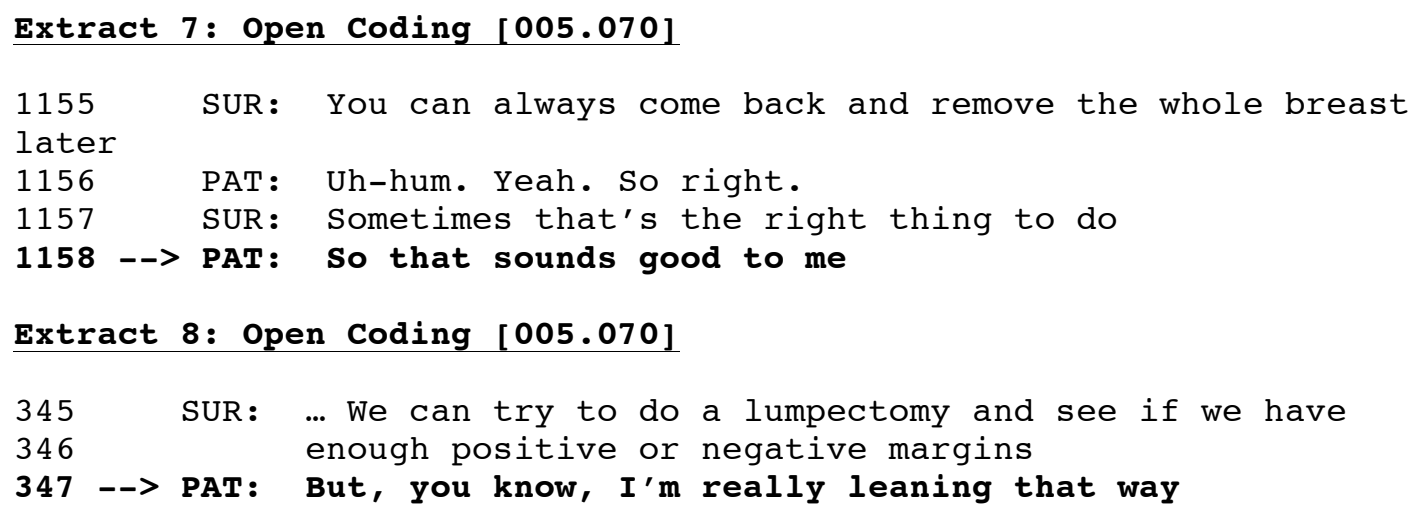

'Saturation' tends to indicate the presence of communicative patterns and leads researchers to the second analytic step in a grounded-theoretical approach, which is referred to as 'axial coding' (Strauss \& Corbin, 1998). In the present thesis, although saturation was reached after coding approximately $75 \%$ of the data, all units were nonetheless open-coded.

\section{Axial Coding}

Axial coding is the process of making connections between 'open codes' in order to identify emergent communicative patterns, which are the 'seeds' of inductively generated theoretic concepts (Strauss \& Corbin, 1998). Axial coding is guided by the constant-comparative method (Strauss \& Corbin, 1998), in which all 'open codes' are 
compared to each other. During axial coding, 'open codes' that represent similar communicative actions are collapsed into larger-order categories. For example, the labels in Extract 2 (i.e., Patient asserts a desire to have surgery 'over' as soon as possible in the face of deciding to undergo chemotherapy first) and Extract 3 (Patient asserts a desire to have surgery 'done' or scheduled 'as soon as possible' after 'talking' with surgeon) were axial-coded into a larger-order category labeled: Patient asserts a preference to have surgery as soon as possible. For another example, the labels in Extract 4 (Patient asserts a preference to have surgery 'here' (i.e., in Portland vs. Florida)) and Extract 5 (Patient asserts a preference to have surgery at the facility 'closest' to her) were axial-coded into a larger-order category labeled: Patient asserts a preference regarding surgery location.

\section{Selective coding}

The third analytic step in a grounded-theoretic approach is referred to as 'selective coding' (Strauss \& Corbin, 1998), which is the process of making connections (again through the constant-comparative method) between 'axial codes' in order to identify even broader (i.e., more general) communicative patterns. Whereas a grounded-theoretic approach almost always produces axial codes (i.e., because categories of action are needed for theory development) selective codes are not always relevant (i.e., It is not always the case that axial codes 'go' or 'fit together'). For one example in the present data, while the open-code label of Extract 6 (Patient asserts a preference to have her presurgical consultation scheduled for 'Wednesday') did not 'fit' into the axial code of Patient asserts a preference to have surgery as soon as possible or into the axial code of Patient asserts a preference regarding surgery location, it did 'fit' with these two axial codes into an even larger category (i.e., a selective code) that was labeled: Patient asserts 
a preference regarding scheduling (i.e., scheduling the time, location, etc. of surgery, follow-up visits, etc.).

\section{Theme generation}

Axial and selective codes potentially make up analytic themes, which are supposed to represent 'robust' patterns of communicative action. Unlike p-values, the definition of 'robust' is typically relative to data sets and the frequencies of their constitutive axial and selective codes. In the present data, a 'theme' was defined as an axial or selective code that occurred in at least $20 \%$ of all cases.

\section{Interactional position of units and themes}

Finally, all units were coded for their interactional position, or where they occurred in the timespan of consultations. Position was calculated as a percentage from $1 \%$ (e.g., the very beginning of consultations) to $100 \%$ (the very ends of consultations) by dividing the line number of the focal unit by the total number of lines in the transcript. Positions of axial and selective codes were calculated by averaging those of their constitutive units. 


\section{Chapter 3: Results}

After coding and analyzing the data, five themes emerged (see above for definition of 'theme'), each with sub-themes. In order of prevalence, these five themes involved patients explicitly asserting preferences regarding: (1) surgical decisions; (2) scheduling; (3) information need; (4) breast-reconstruction decisions; and (5) radiation decisions. Each theme (and its associated sub-themes) will be reviewed in its own subsection with data exemplars. Thematic frequencies (i.e., the percentage of visits in which the theme or subtheme emerged at least once) and thematic densities (i.e., the number of times the theme or subtheme emerged when it was present) will also be reported. As noted in the data/methods section, in transcripts of all data exemplars, patients are referred to as 'PAT' (in left margins), patients' companions (e.g., sisters, husbands, friends etc.) are referred to as 'CPN,' surgeons are referred to as 'SUR,' and surgical assistants are referred to as 'AST.' In transcripts of all data exemplars, the focal assertive utterance is represented in boldface type and indicated by an arrow (-->) in the left-hand margin.

\section{Theme 1: Asserting preferences for/against surgical decisions}

The most prominent theme involved patients explicitly asserting their preferences for/against surgical decisions, such as those for lumpectomy (i.e., removal of a cancerous portion of a breast) or mastectomy (i.e., removal of an entire breast). This theme emerged in $60 \%$ of all visits (i.e., thematic frequency), and when it emerged, it occurred an average of 2.1 times (i.e., thematic density). The average interactional position of this theme was $58 \%$ (i.e., these assertions tended to occur in the 'late middles' of consultations, when surgeons were most likely to be presenting and discussing surgical 
treatment options). This theme was a selective code in that it contained three subthemes, which were axial codes. Two of these subthemes - including 'asserting preference for lumpectomy' and 'asserting preference for mastectomy' - constituted themes in their own right, insofar as they occurred in $20 \%$ or more of all visits (see below for individual thematic frequencies and densities). The third subtheme, which was relatively less prominent, was 'asserting preference against mastectomy.' Each subtheme will be discussed in turn below.

\section{Subtheme 1a: Asserting preference for lumpectomy.}

The subtheme of patients 'asserting preferences for lumpectomy' was an axial code that occurred in $35 \%$ of all visits, and when it occurred, it did so an average of 1.6 times. This sub-theme had an average interactional position of 59\%. For the first of three examples, see Extract 9. Prior to this extract, the patient has reported that she has 'heard about' women having breast complications following mastectomies (i.e., the removal of the entire breast). At lines 427-428, the surgeon is reporting statistics associated with these complications.

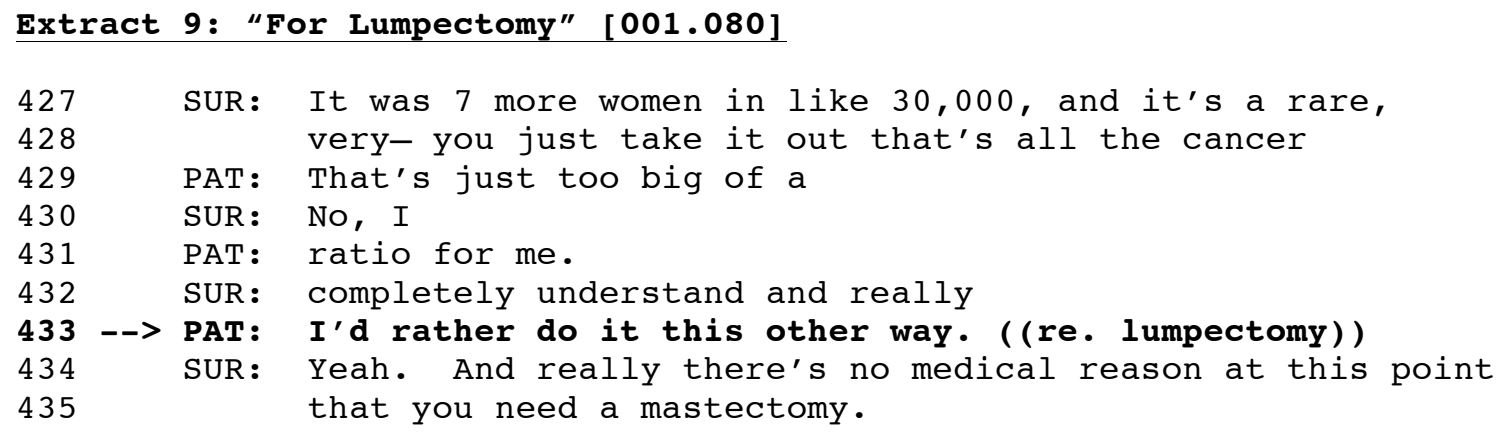

At lines 429-431, the patient asserts her lack of acceptance of the risks being discussed, "That's just too big of a ratio for me." At line 433, of her own initiative, the patient explicitly asserts a preference for a lumpectomy (i.e., the removal of a cancerous 
portion of her breast): "I'd rather do it this other way." The surgeon immediately accepts the patient's decision with "Yeah" (line 434), and goes on to support her decision: "And really there's no medical reason at this point that you need a mastectomy" (lines 434435).

For a second example, see Extract 10. Prior to this extract, the surgeon has presented both lumpectomy and mastectomy as surgical-treatment options, but the patient has not yet made a decision regarding such options. At line 429, when the patient asks, "How soon can we set this up?", she is referring to a date for surgery in general, not for a specific type of surgery.

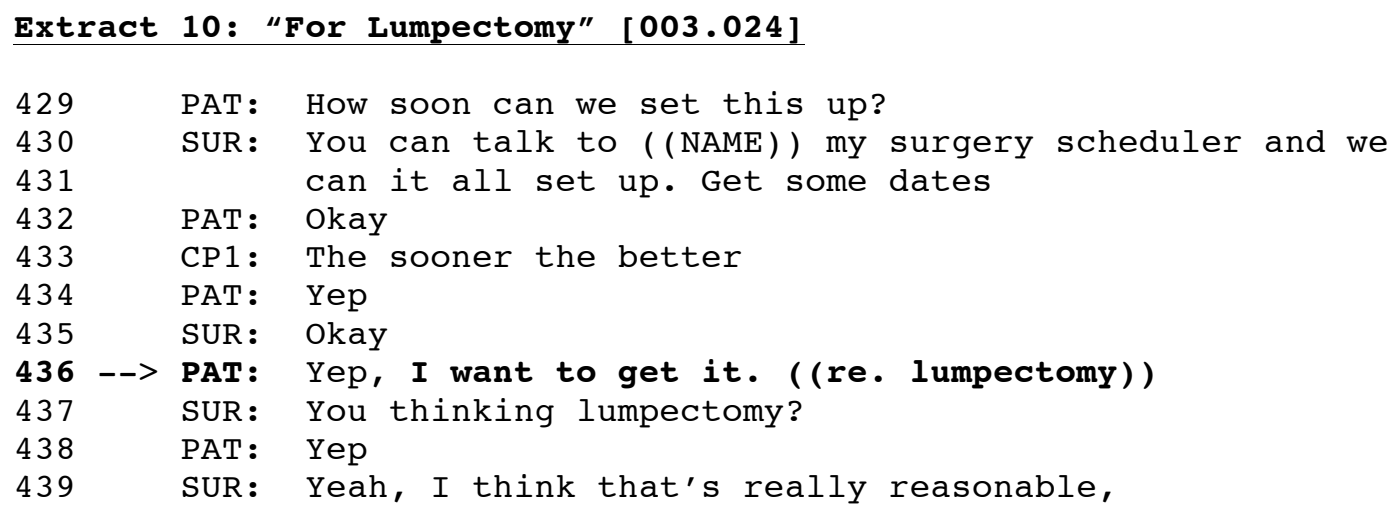

After the surgeon agrees, "Okay" (line 435), to a prompt date for surgery in general, the patient explicitly asserts a preference for lumpectomy, and does so of her own initiative: "I want to get it" (line 436). After confirming that the patient is advocating for lumpectomy (lines 437-438), the surgeon agrees with the patient's decision "Yeah" (line 439) and supports it: "I think that's really reasonable" (line 439).

For a third and final example, see Extract 11. At lines 386-394, the surgeon is comparing and contrasting lumpectomy and mastectomy as surgical procedures. 


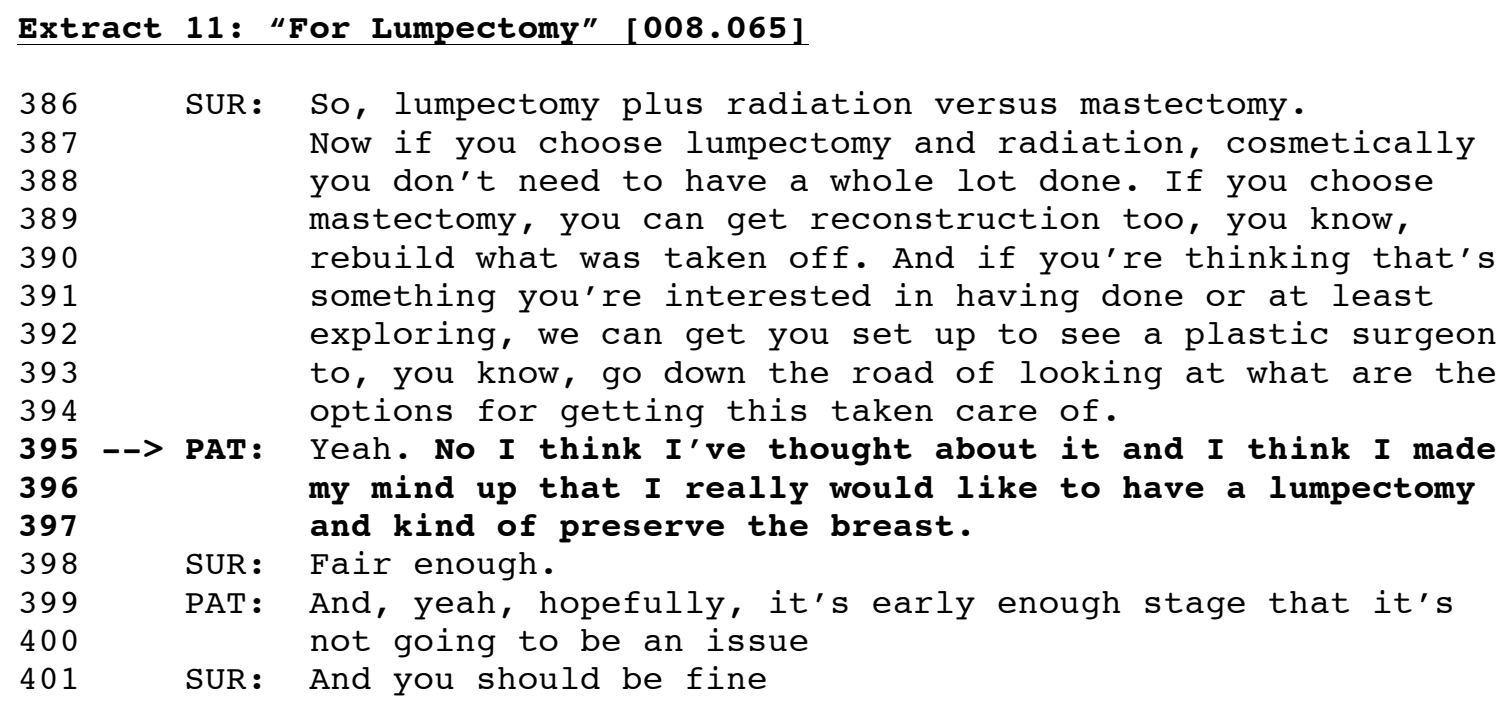

At lines 395-397, the patient asserts her preference for a lumpectomy: "I

think I've thought about it and I think I made my mind up that I really would like to have a lumpectomy..." At line 398, the surgeon accepts the patient's decision, "Fair enough.", and eventually supports it: "And you should be fine" (line 401).

In sum, in each case (Extracts 9-11, above), patients explicitly assert a preference for a lumpectomy, and do so of their own initiative (i.e., independently of surgeons' prompting). Furthermore, in each case, surgeons treat patients' assertions as conversational actions to be responded to by agreeing with patients' decisions, and in each case by continuing to support patients' decisions.

\section{Subtheme 1b: Asserting preference for mastectomy.}

The subtheme of patients asserting preferences for a mastectomy surgery was an axial code that occurred in $25 \%$ of all visits, and when it occurred, it did so an average of 2.04 times. This sub-theme accrued an average interactional position of $56 \%$. For the first of three examples, see Extract 12. Prior to this extract, as part of her review of surgical treatment options, the surgeon has discussed the possibility of radiation accompanying 
lumpectomy. The patient has expressed apprehension about radiation and, at lines 327-

332, the surgeon justifies her need to review radiation as an option.

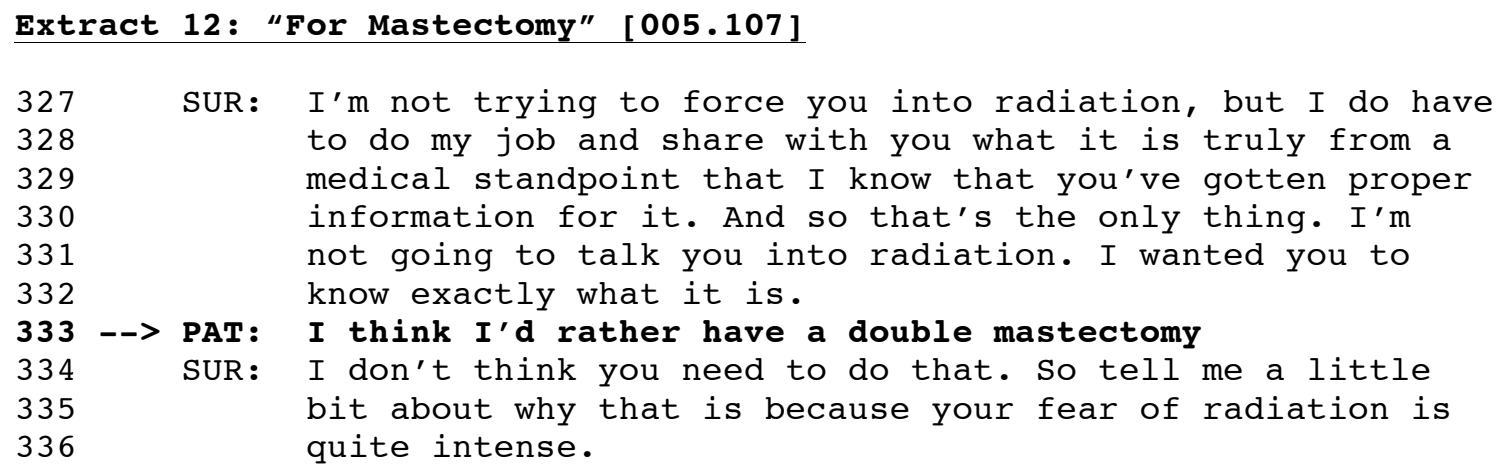

At line 333, the patient, of her own volition, explicitly asserts her preference for a mastectomy: "I think I'd rather have a double mastectomy." Unlike in Extracts 1-3 (above), the surgeon responds by resisting the patient's decision: “I don't think you need to do that" (line 334-335).

For a second example, see Extract 13. Prior to this extract, the surgeon has explained the differences between lumpectomy and mastectomy, and the patient has discussed her family history of breast cancer. At lines 404-411, the patient is discussing her sister's breast cancer generally, and her lumpectomy specifically.

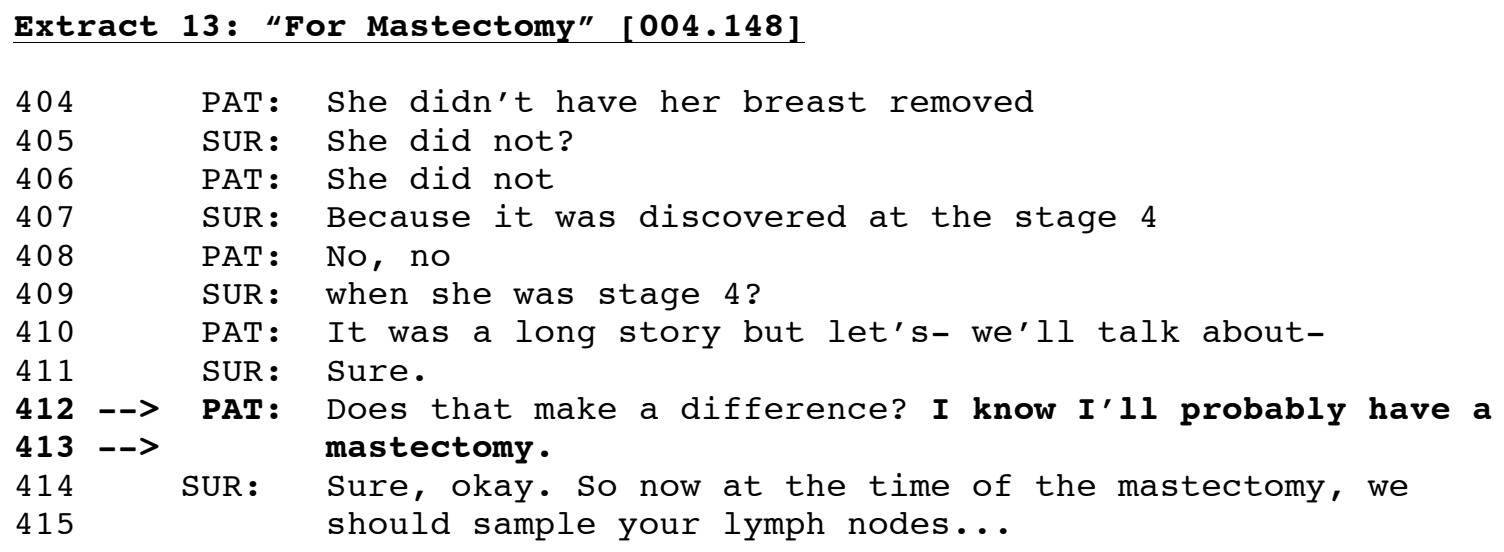

In contrast to her sister's lumpectomy decision, at lines 412-413, the

patient, of her own initiative, asserts her preference for a mastectomy: "I know I'll 
probably have a mastectomy." The surgeon responds by accepting the patient's assertion, "Sure, okay" (line 414).

For a final example, see Extract 14. Prior to this extract, the patient and companion have asked the surgeon about the differences between lumpectomy and mastectomy procedures, and have inquired about reconstruction options. At lines 360362 , the surgeon is discussing alternatives to mastectomy.

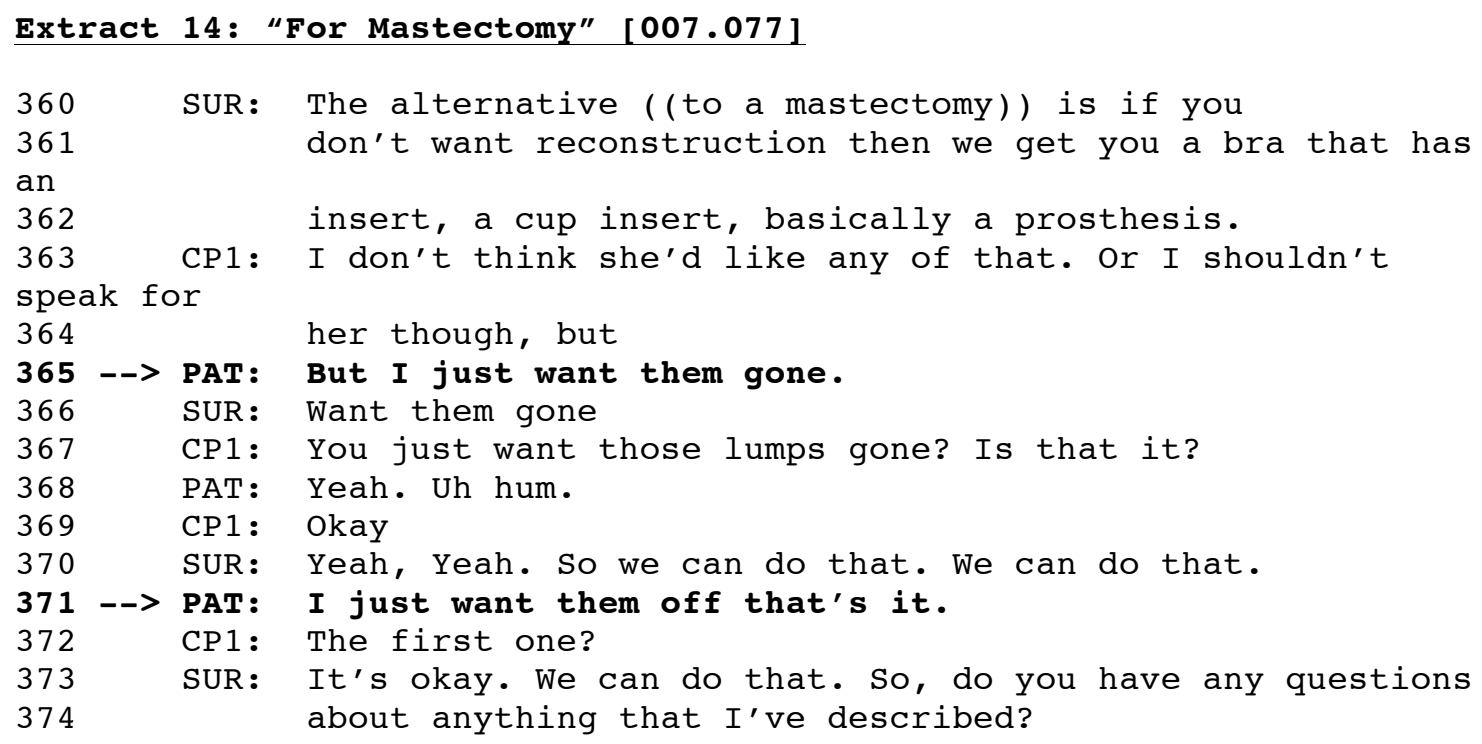

At line 365, the patient, of her own initiative, asserts a preference for a double mastectomy: "I just want them gone." Both the surgeon (at line 366) and the companion (at line 367) request confirmation of the patient's preferences, and the patient re-iterates her desire for a double mastectomy at line 371: "I just want them off that's it." The surgeon responds by reassuring the patient, "It's okay" (line 373) and then accepting the patient's preferences: "We can do that" (line 373).

In sum, in each case (Extracts 12-14, above), patients explicitly assert a preference for a mastectomy, and do so of their own initiative (i.e., independently of surgeons' prompting). Furthermore, in each case, surgeons treat patients' assertions as 
conversational actions to be responded to by either agreeing with (and accepting), or disagreeing with, patients' decisions.

\section{Sub-theme 1c: Asserting preference against mastectomy.}

The third sub-theme of 'asserting preference against mastectomy' was an axial code that only occurred in $12 \%$ of all visits, and thus did not meet the $20 \%$ 'threshold' to itself constitute a robust theme; when it occurred, it did so an average of 1.6 times. The 'against mastectomy' sub-theme had an average interactional position of $59 \%$.

For the first of three examples, see Extract 15. Prior to this extract, the surgeon has explained a lumpectomy procedure (i.e., removing a partial section of the breast, or just a 'lump'). At line 156, the surgeon is discussing an alternative procedure of mastectomy (i.e., removing the entire breast).

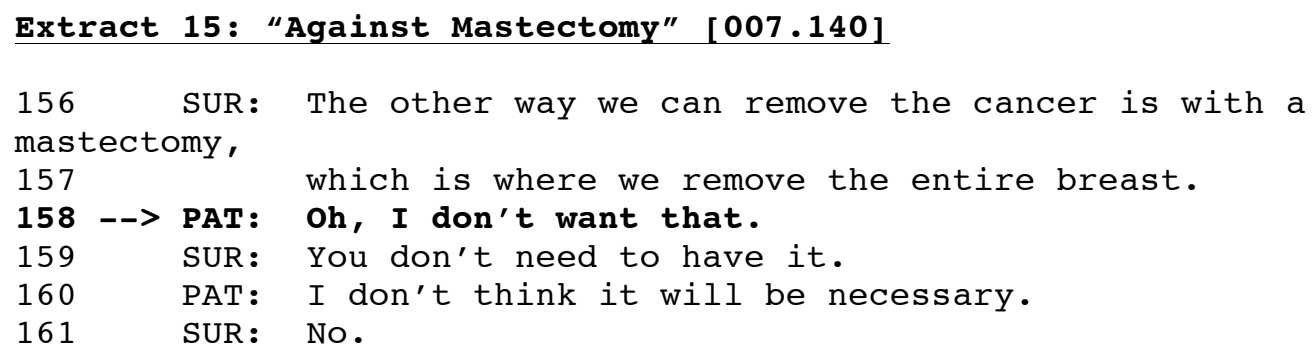

At line 158, the patient, of her own initiative, advocates against mastectomy: "Oh, I don't want that." The surgeon responds by assuring the patient that she does not need a mastectomy, "You don't need to have it" (line 159), and then agrees with the patient's assertion (at line 160) that a mastectomy is not necessary: "No" (line 161).

For a second example, see Extract 16. Prior to this extract, and culminating at lines $183-185$, the surgeon has explained why so many women have 
historically chosen a mastectomy, even though they may have been eligible for a lumpectomy (given recent science and technology).

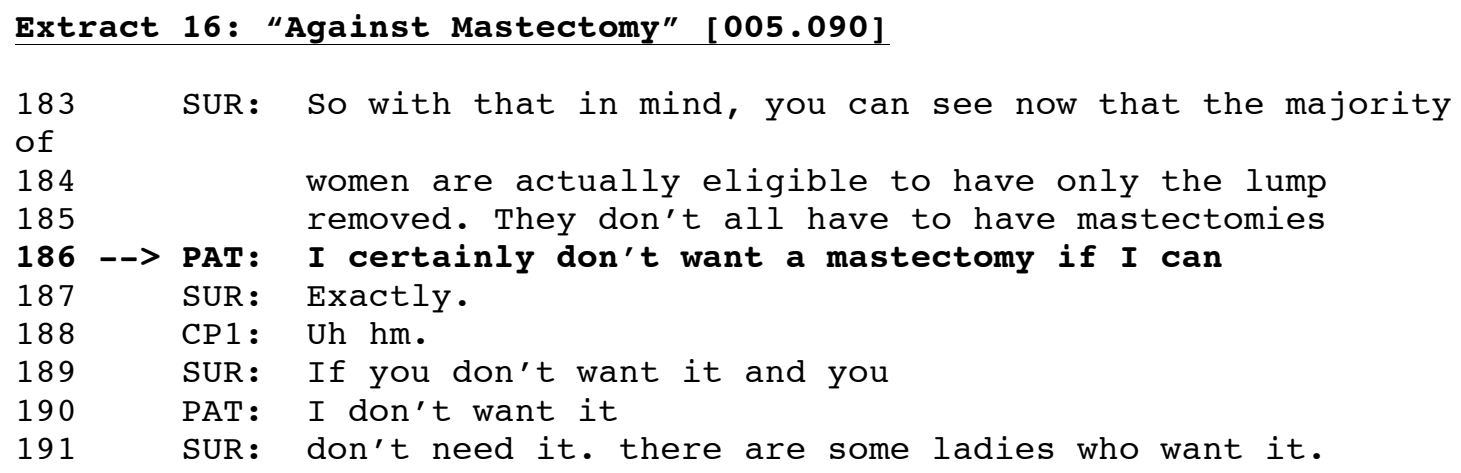

At line 186, the patient aligns with the surgeon's explanation, strongly and explicitly asserting her preference against mastectomy: "I certainly don't want a mastectomy..." The surgeon responds by emphatically agreeing with the patient: "Exactly" (line 187).

For a third example, see Extract 17. At lines 873-879, the surgeon informs the patient that some women choose mastectomy and provides a reason why, namely that, when an entire breast is removed, patients do not have to engage in extremely regular testing (e.g., quarterly mammography) to monitor for recurrence.

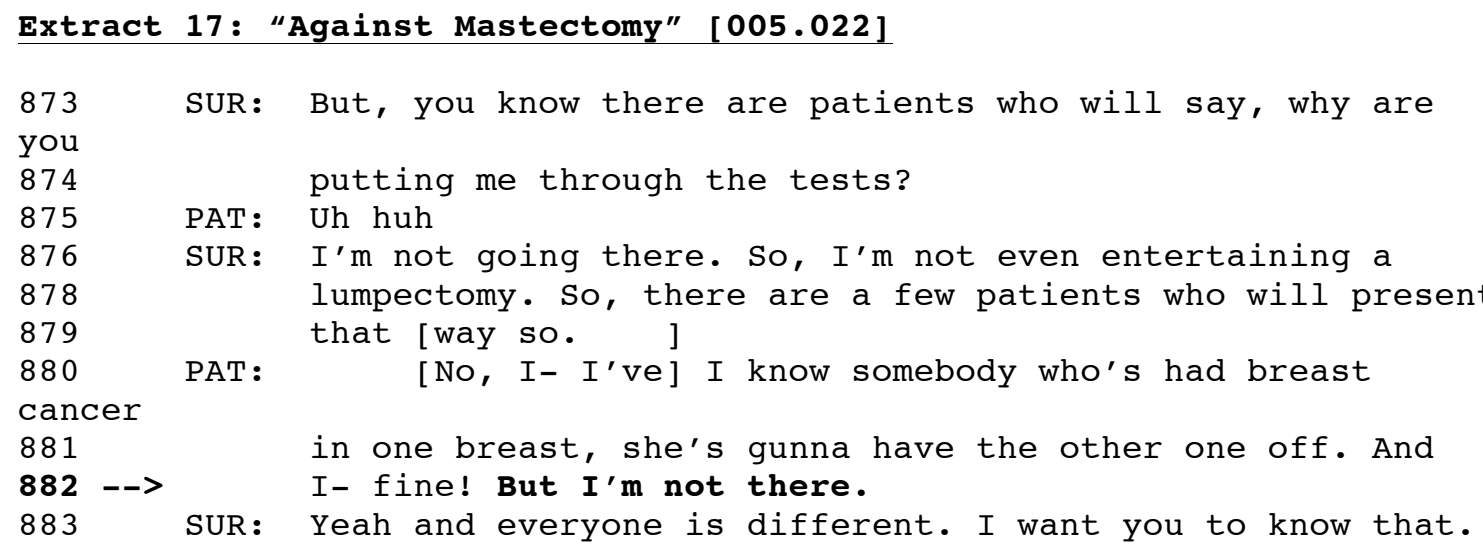

At lines 880-882, the patient displays her understanding of the physician's explanation by relating a story of an acquaintance who (for the reasons previously laid 
out by the physician) opted for a double mastectomy (i.e., to avoid testing in either breast). At line 882, the patient accepts her acquaintance's decision, “fine!", but then explicitly asserts her preference against mastectomy: "But I'm not there.” The physician responds by agreeing with the patient's assertion, "Yeah" (line 883), and supporting the patient's decision (relative to that of her acquaintance): “...everyone is different. I want you to know that."

In sum, in each case (Extracts 15-17, above), patients explicitly assert a preference against mastectomy, and do so of their own initiative (i.e., independently of surgeons' prompting). Furthermore, in each case, surgeons treat patients' assertions as conversational actions to be responded to. Note that each of these cases come in the context of physicians discussing and explaining the pros and cons of lumpectomy (with radiation) versus mastectomy. By asserting a preference 'against mastectomy,' patients are indirectly asserting a preference 'for lumpectomy.' Although this axial code was labeled 'asserting preference against mastectomy' - because those are the words being used by patients - conceptually this code fits very 'cleanly' into subtheme 1a: 'asserting preference for lumpectomy.' Along these lines, if we collapse subtheme 1c (i.e., 'against mastectomy') into subtheme 1a (i.e., 'for lumpectomy'), then the new, more robust subtheme 1a, which occurred in $41 \%$ of all visits and, when it occurred, it did so an average of 1.8 times.

\section{Theme 2: Asserting preferences regarding scheduling}

The second most prominent theme involved patients explicitly asserting their preferences about matters related to scheduling. This theme emerged in $48 \%$ of all visits (i.e., thematic frequency), and when it emerged, it occurred an average of 2.01 times (i.e., 
thematic density). The average interactional position of this theme was $76 \%$ (i.e., typically after surgeons had presented and discussed treatment options, and thus more toward the 'closing' of consultations). This theme was a selective code in that it contained three subthemes, which were axial codes. Only one of the subthemes, 'asserting preference for scheduling surgery as soon as possible,' constituted a theme in its own right, insofar as it occurred in more than $20 \%$ of all visits. The other two subthemes - 'asserting a preference for treatment location' and 'asserting a preference for general scheduling matters' - did not themselves constitute robust themes. Each subtheme will be discussed in turn below.

\section{Subtheme 2a: Asserting a preference for scheduling surgery as soon as}

\section{possible.}

The subtheme of 'asserting a preference for scheduling surgery as soon as possible' was an axial code that occurred in $40 \%$ of all visits, and when it occurred, it did so an average of 1.6 times. The average interactional position of this sub-theme was $71 \%$.

For the first of three examples, see Extract 18. Prior to this extract and culminating at lines 780-783, because of the size and nature of the patient's tumor, the physician has recommended that she undergo chemotherapy prior to surgery (in order to shrink the tumor and begin treating the patient systemically as soon as possible in order to prevent possible spread).

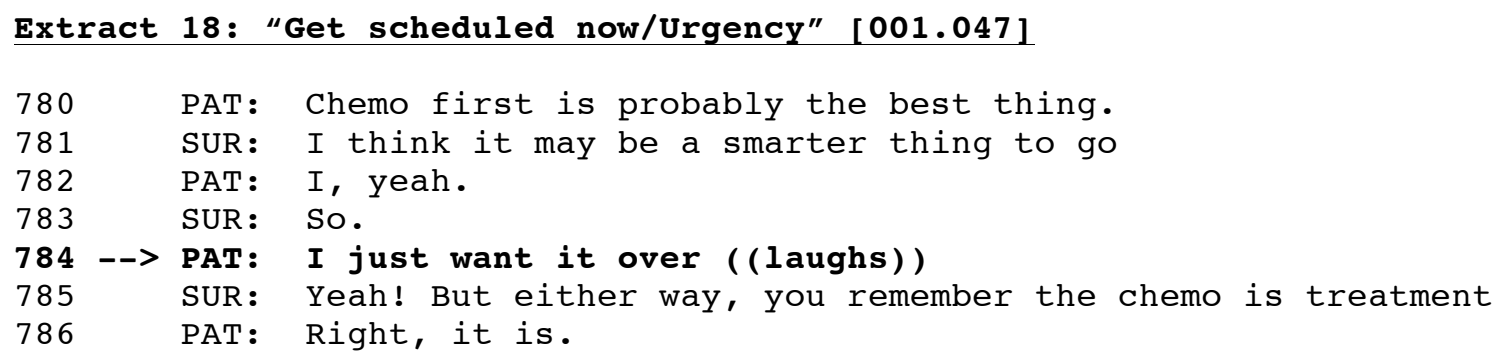


After the patient agrees with the physician's recommendation to begin chemotherapy first (i.e., before surgery), "yeah" (line 782), the patient asserts: "I just want it over." Here, the patient is referring (with 'it') to surgery (i.e., the removal of the tumor from her breast). This is understood by the physician, who hears the patient's assertion as implying that 'surgery' (vs. chemotherapy) is the 'real' treatment.

Specifically, after emphatically agreeing with the patient's assertion, "Yeah!” (line 785), the physician reassures the patient that "chemo is treatment" (line 785).

For a second example, see extract 19. Prior to this extract, the patient's companion asked the surgeon if there were other issues to consider before making a decision. The patient had previously made it clear that she is considering a lumpectomy.

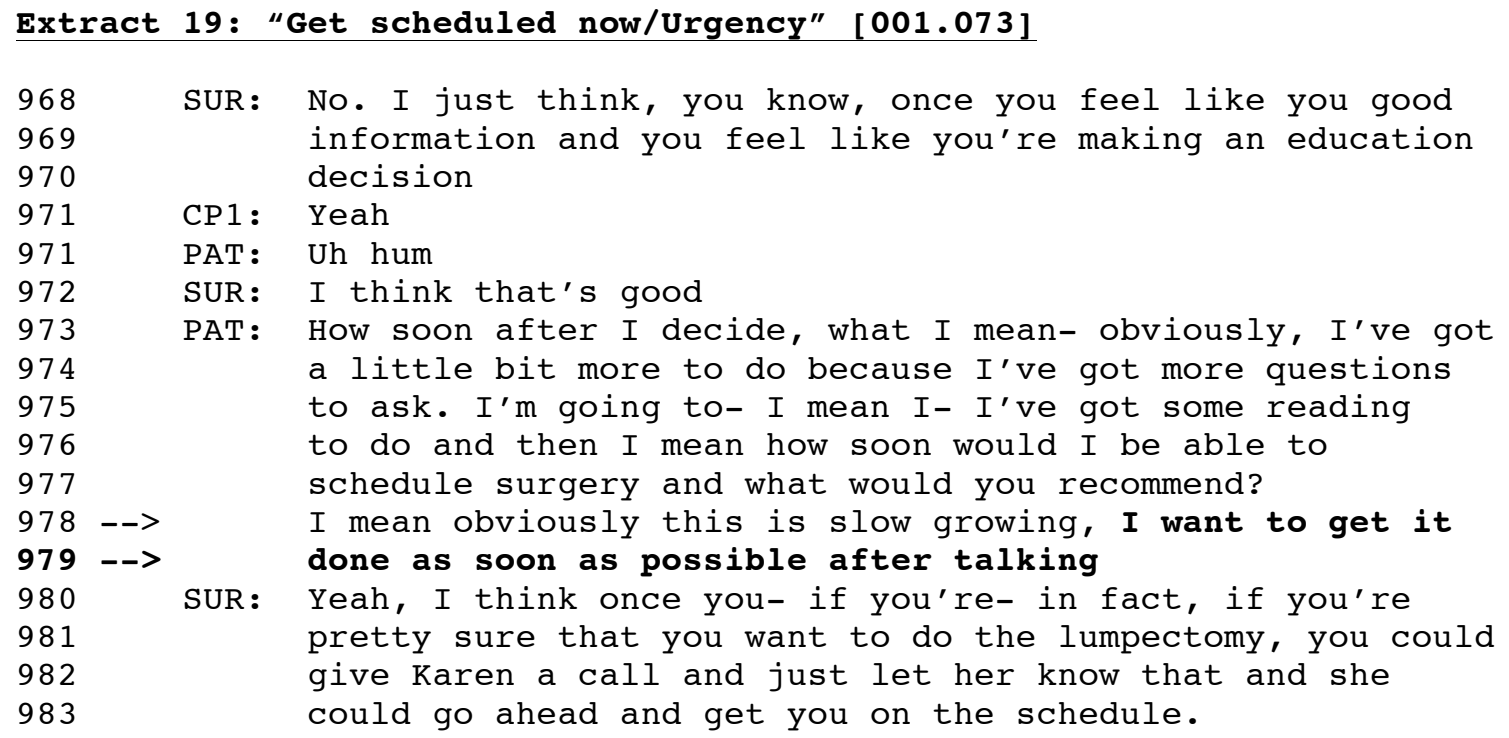

After asking, "how soon would I be able to schedule surgery" (lines 976977), the patient explicitly asserts her preference to "get it done as soon as possible after talking" (i.e., after the current visit). The surgeon response by agreeing with the patient's preference: "Yeah" (line 980), and then provides scheduling information (lines 980-983). 
For a third example, see extract 20. At lines 538-546, the surgeon

recommends surgery "within the next 6 to 8 weeks," and then justifies her

recommendation. In contrast, at lines 546-548, the surgeon says, "I don't think this is an emergency," and that the surgery is "not something you need to schedule next week."

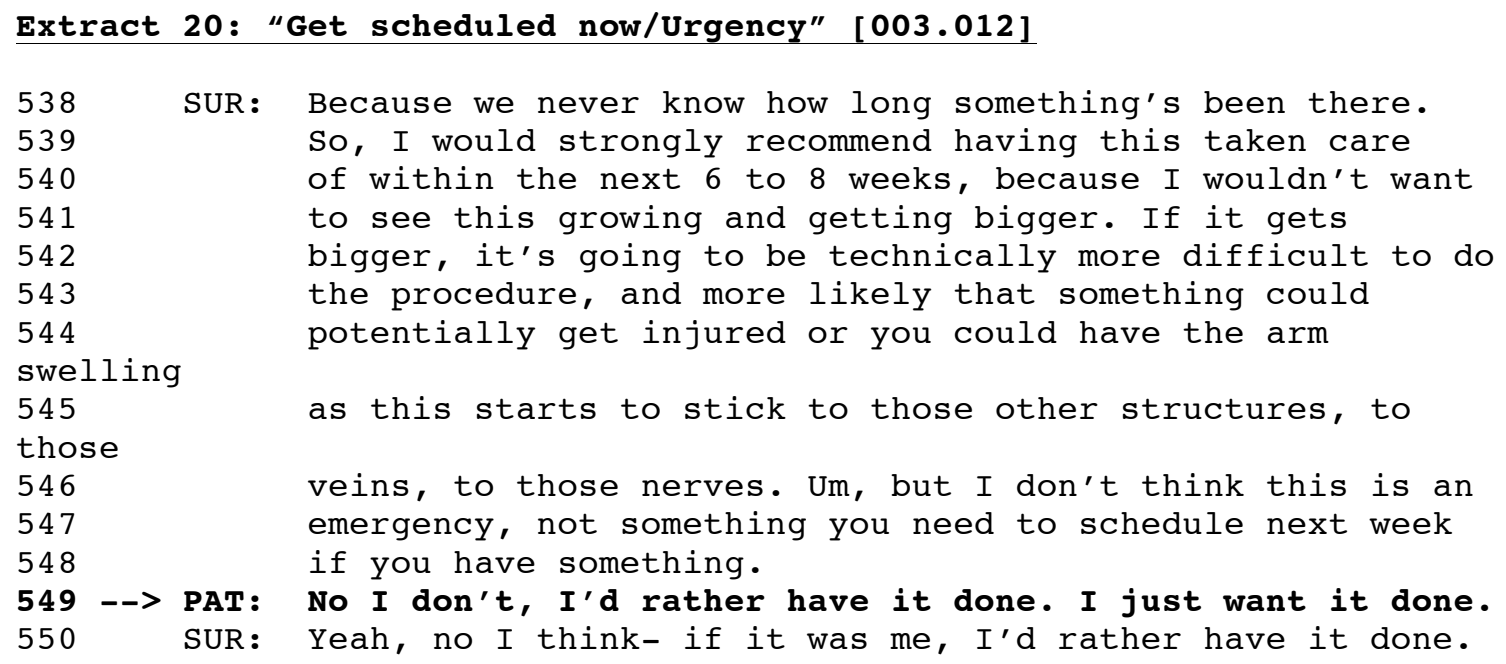

At line 549, the patient explicitly resists the surgeon's offer to delay surgery by asserting: "No I don't [want to wait] ... I'd rather have it done. I just want it done." The surgeon responds by agreeing with the patient's preference, "Yeah" (line 550), and then supporting it: "if it was me, I'd rather have it done."

\section{Subtheme 2b: Asserting a preference for treatment location.}

The subtheme of 'asserting a preference for treatment location' was an axial code that occurred in $19 \%$ of all visits, and when it occurred, it did so an average of 1.6 times. This sub-theme had an average interactional position of $74 \%$. In this case, 'treatment' referred not only to surgery, but also chemotherapy, radiation, etc. It is worth noting that, in contrast to prior types of patients' assertions (representing prior subthemes), those regarding treatment location were relatively more actively solicited by physicians' questions or prompts. 
For a first example, see extract 21. As context, the patient and her companion go to Florida for four and a half months every year. The patient has already decided that she will undergo chemotherapy before surgery. At lines 1047-1048, the companion asks the patient if she would like to complete her treatment in Florida.

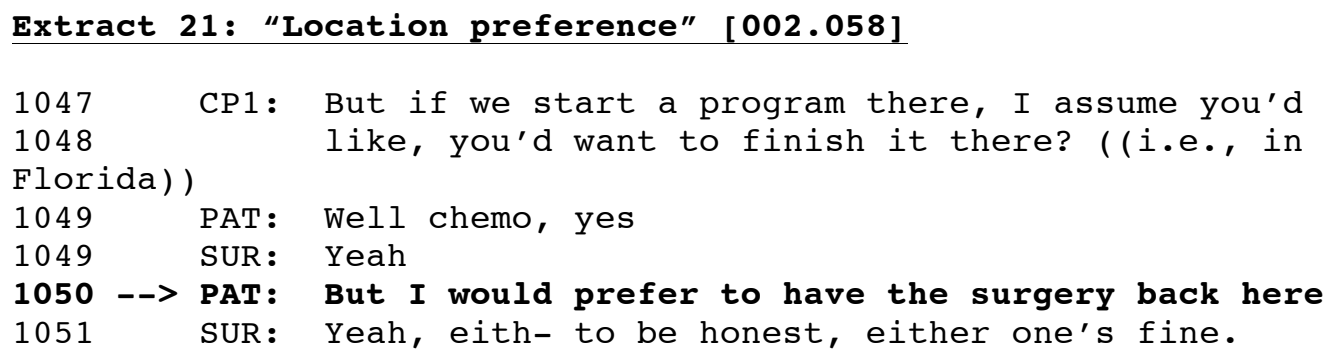

In response to the companion's question, the patient indicates her preference for completing chemotherapy in Florida (line 1049), but surgery in Portland (line 1050). The surgeon treats the patient's preference as an action to be responded to by agreeing with it: "Yeah."

For a second example, see extract 22. As part of a larger, prior discussion of where surgery will be performed, the surgeon offers her one convenient possibility: "St. Vincent is closer to you."

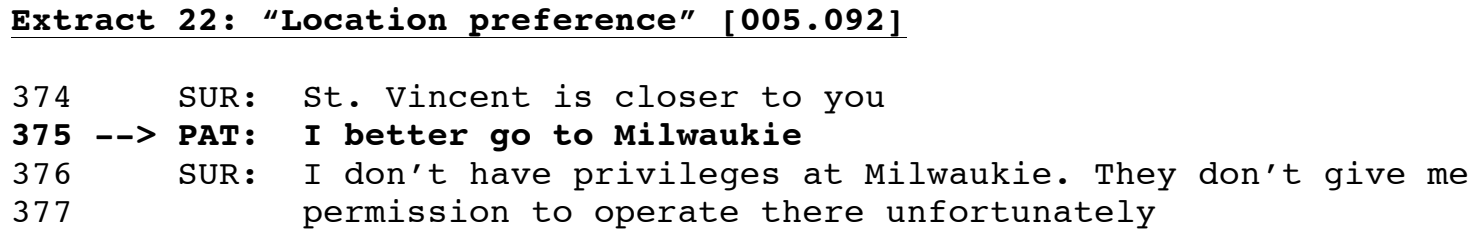

At line 375, the patient answers by rejecting the surgeon's offer by explicitly asserting an alternative preference: "I better go to Milwaukie." At lines 376377 , the surgeon denies the patient's preference because she does not "have privileges at Milwaukie." 
For a third example, see extract 23. At lines 370-373, the surgical assistant offers the patient two possible locations at which to receive radiation.

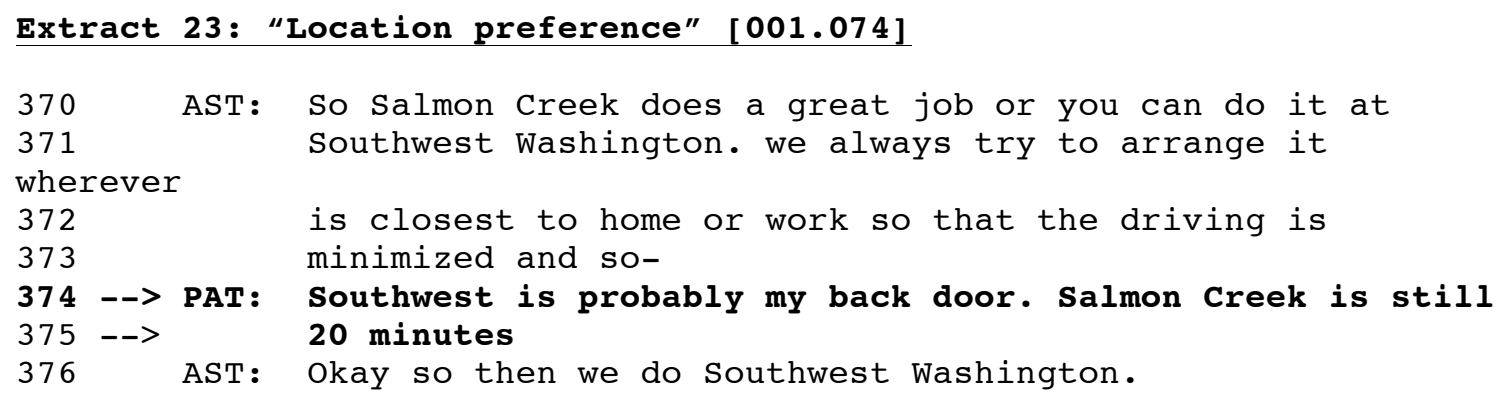

In response, the patient asserts a preference for "Southwest" (line 374; vs.

“Salmon Creek). The surgical assistant accepts the patient's preference: “Okay so then we do Southwest Washington" (line 376).

\section{Subtheme 2c: Asserting a preference for general scheduling matters.}

The third subtheme of 'asserting a preference for general scheduling matters' will not be discussed in detail because of its relative infrequency, occurring in only $11 \%$ of visits; in these visits, the subtheme occurred an average of 1.2 times. This sub-theme had an average interactional position of $83 \%$. General scheduling matters involved issues such as patients asserting preferences regarding specific dates/timelines for surgery, other treatments, and follow-up visits. For a single example, see Extract 6 (which is reproduced again below).

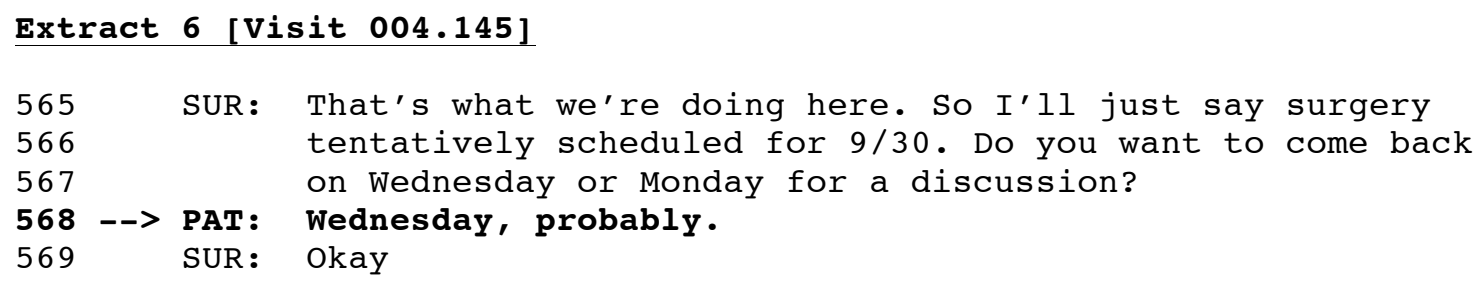

Theme 3: Asserting a preference for (more) information 
The third most prominent theme involved patients explicitly asserting their preferences for (more) information. This theme emerged in $31 \%$ of all visits (i.e., thematic frequency), and when it emerged, it occurred an average of 1.8 times (i.e., thematic density). The average interactional position of this theme was $49 \%$ (Again, in the 'middles' of consultations). This was an axial code that contained assertions for a variety of different types of information, none of which occurred frequently enough to constitute a 'theme' in their own right. Importantly, this theme did not involve patients asking specific questions (Note that 'patient question asking' is a conceptually and empirically separate element or variable of patient-centered communication). Rather, this theme centered around patients asserting preferences for either (more) information generally, or for more information about specific facets of their condition or treatment, such as about pathology, diagnosis, prognosis, genetics, medication, and so on.

For a first example, see Extract 24. Prior to this extract, the patient has disrobed and been physically examined by the surgeon, a process that always (in this office) precedes a much longer (e.g., 30-45 minute) discussion about the patient's cancer and her treatment options. The surgeon has told the patient that she will briefly leave to allow the patient to 'get dressed.' At lines 90-91, the surgeon justifies her procedure: "I do this in stages because it's more comfortable for someone to be dressed."

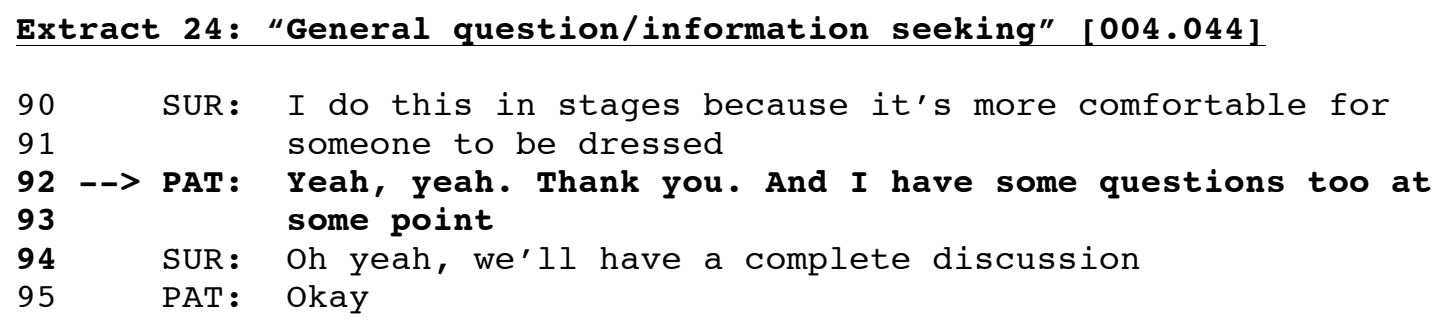


At lines 92-93, before the surgeon leaves the room, the patient explicitly asserts her desire to be able to 'ask questions" "at some point" during the subsequent discussion. Here, the patient is not asking a specific question, but rather indicating that she desires certain types of information.

For a second example, see Extract 25. Prior to this extract, the surgeon has been explaining the details of a pathology test, and the patient has expressed feeling 'overloaded' with information. At line 273, the surgeon reassures the patient by telling her that she will leave the office with written information about the test: "You're going to go home with this sheet."

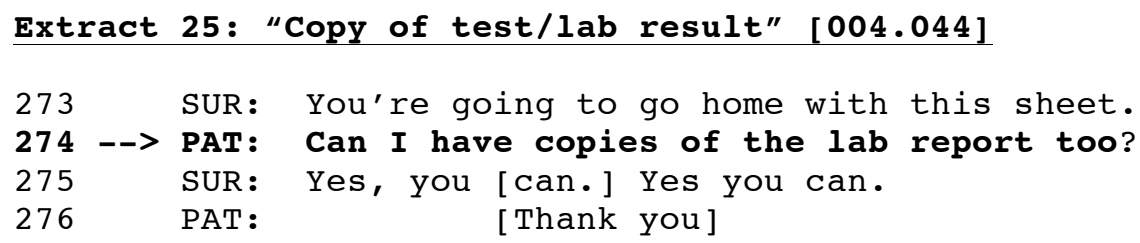

At line 274 , the patient additionally requests a copy of the actual lab report of the pathology test. Rather than asking a question about the test, the patient asserts her preference for more, and more specific, information about the test.

For a third example, see Extract 26. Much earlier, the surgeon and patient had discussed genetic testing and the type of information it would produce relative to the patient's treatment. Here, at lines 294-297, the surgeon is recommending that the patient undergo chemotherapy prior to surgery, including mastectomy. 
Extract 26: "Genetic Information" [001.006]

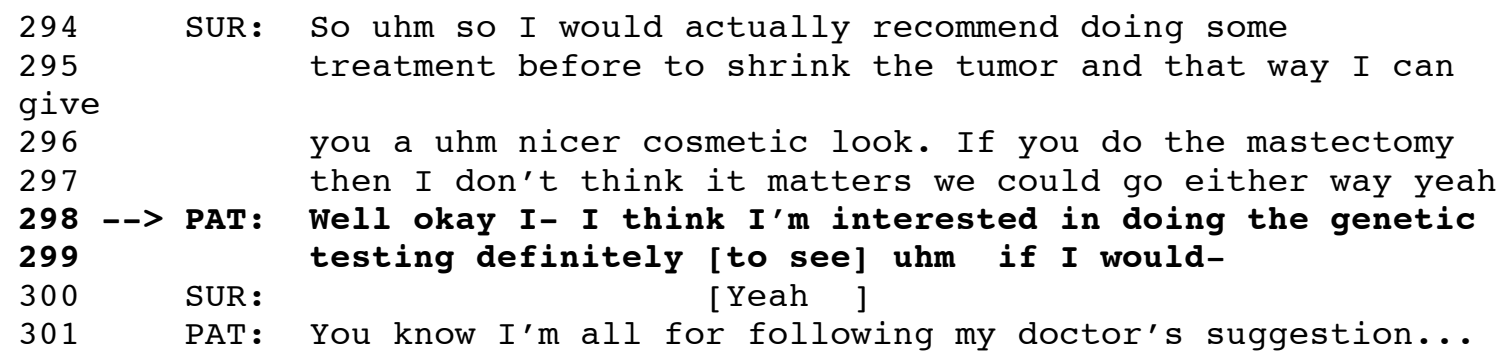

At lines 298-299, the patient resists the surgeon's recommendation by explicitly asserting a preference for genetic testing: "Well ... I think I'm interested in doing the genetic testing..." As the patient goes on to say, while she is "all for following my doctor's suggestion" (line 301), she desires more information before agreeing to initially undergo chemotherapy.

\section{Theme 4: Asserting a preference for/against reconstructive surgery}

The fourth most prominent theme involved patients explicitly asserting their preferences for/against reconstructive surgery. Breast reconstruction involves plasticsurgical procedures that help restore the look and feel of breasts after either a lumpectomy (for example, in the case of relatively large lumps being removed from relatively small-breasted women, which can disrupt breast symmetry) or a mastectomy (for example, reconstructing an entire breast). Note that, when done as part of breastcancer treatment, insurance covers most forms of breast reconstruction, including breast enlargements and reductions.

This theme emerged in $33 \%$ of all visits (i.e., thematic frequency), and when it emerged, it occurred an average of 1.9 times (i.e., thematic density). The average interactional position of this theme was $60 \%$. This theme was a selective code in that it contained two subthemes, which were axial codes. Only one of these subthemes - that is, 
'asserting preference for reconstructive surgery' - constituted a robust theme in its own right, insofar as it occurred in $20 \%$ or more of all visits (See below for individual thematic frequencies and densities). The second subtheme, which was much less prominent, was 'asserting a preference against reconstructive surgery.' Each subtheme will be discussed in turn below.

\section{Subtheme 4a: Asserting a preference for reconstructive surgery.}

The subtheme of patients 'asserting preferences for reconstructive surgery' was an axial code that occurred in $30 \%$ of all visits, and when it occurred, it did so an average of 1.6 times. The average interactional position of this sub-theme was $62 \%$ (i.e., in the 'latemiddles' of consultations). For the first of three examples, see Extract 27. As context, the surgeon and patient - who is facing a double mastectomy - are discussing the financial implications of reconstructive surgery, and specifically its coverage by insurance. At lines 841-850, the surgeon explains the history and rationale of insurance covering reconstructive surgery.

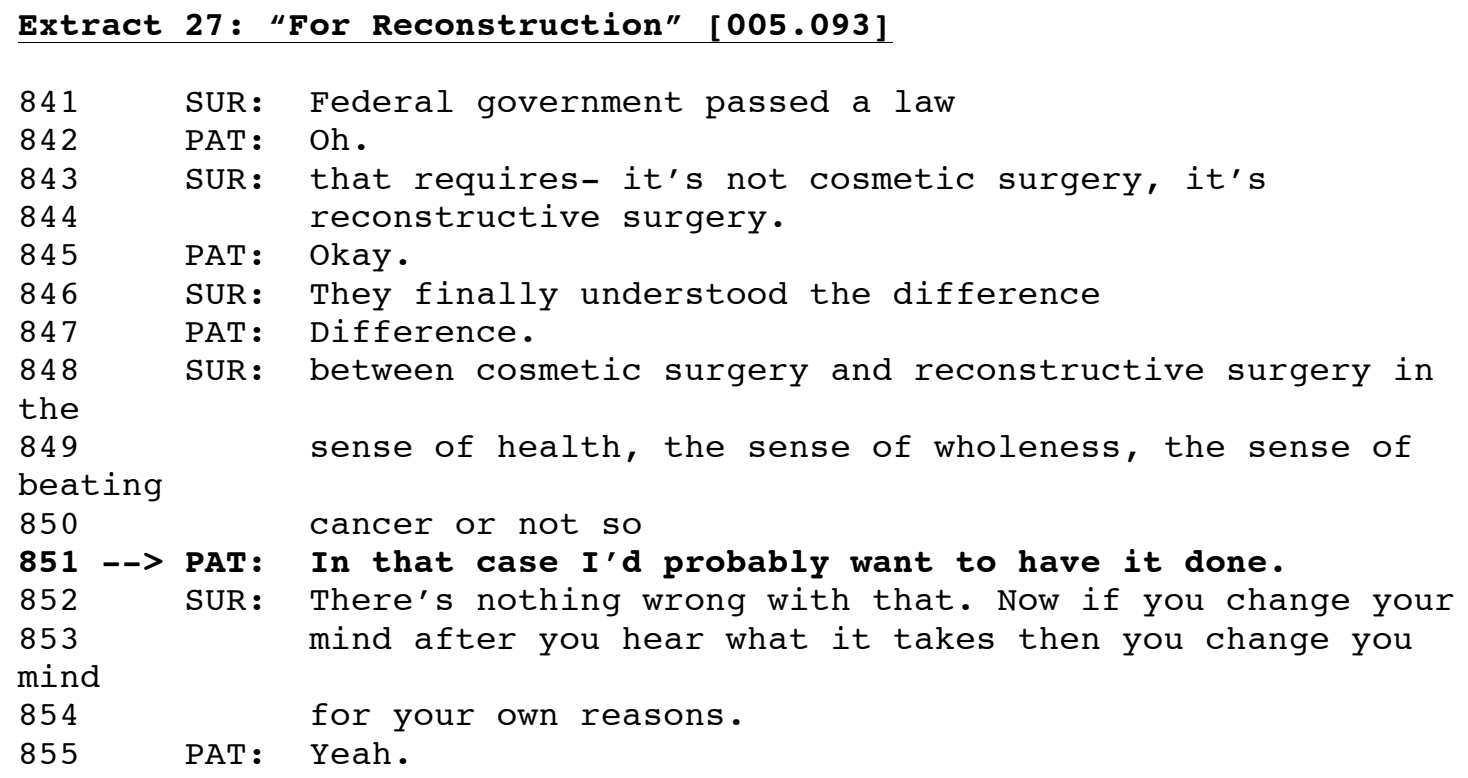


After the surgeon's explanation, the patient explicitly asserts her preference for having reconstructive surgery: "In that case I'd probably want to have it done" (line 851). The surgeon responds by reassuring the patient about her preference: “There's nothing wrong with that" (line 852).

For a second example, see extract 28. As context, this patient is experiencing breast cancer for the second time, and she did not elect to have reconstructive surgery after her first surgery (i.e., for her first cancer). At lines 150-152, the surgical assistant informs the patient that reconstructive surgery is "still always an option" for the treatment of her second cancer.

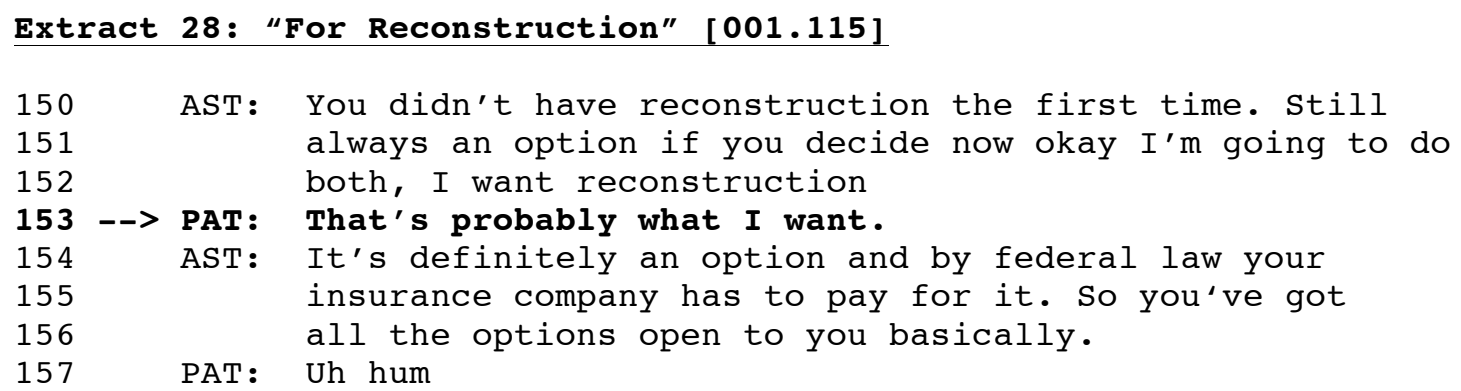

At line 153, the patient responds to the surgical assistant's offer by accepting it, explicitly asserting her preference for reconstructive surgery: "That's probably what I want." The surgical assistant goes on to encourage the patient to consider reconstructive surgery (lines 154-156).

For a third example, see Extract 29. Prior to this extract, the patient has decided to get a mastectomy based on the recommendation of another physician. At line 580 , the patient begins to inform the physician about her decisions regarding reconstructive surgery. 


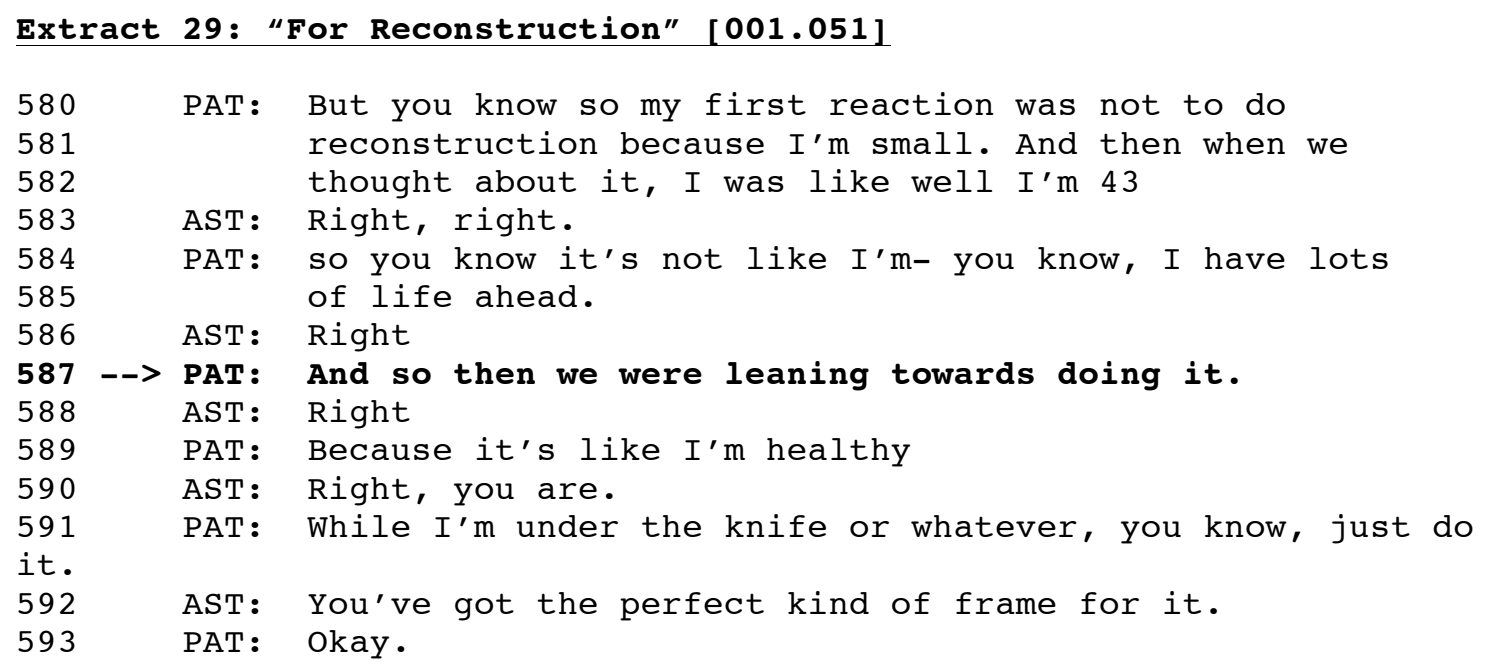

At line 587, the patient explicitly asserts her (and her husband's) preference for reconstructive surgery: "And so then we were leaning towards doing it." At line 591, the patient reiterates her preference for having reconstruction immediately, that is, as part of (or at the same time as) her mastectomy surgery: "While I'm under the knife or whatever, you know, just do it." At line 592, the surgical assistant supports and encourages the patient's decision: "You've got the perfect kind of frame for it."

\section{Subtheme 4b: Asserting a preference against reconstructive surgery.}

In a minority of cases, patients asserted a preference 'against' reconstructive surgery. This subtheme was an axial code that occurred in only $7 \%$ of all visits, and when it occurred, it did so an average of 1.5 times. The average interactional position of this sub-theme was 55\%. For one example, see Extract 30 . Prior to this extract, and culminating in lines 411-412, the surgeon has been explaining the pros, cons, and contingencies associated with having, or not having, reconstructive surgery after a lumpectomy (i.e., a relatively less intrusive surgery compared to a mastectomy). 
Extract 30: "Against Reconstruction" [001.011]

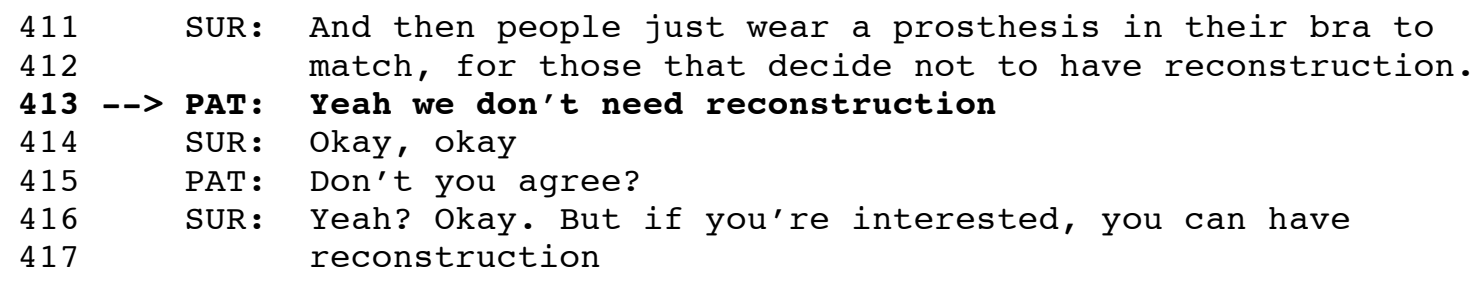

At line 413, the patient explicitly asserts her preference to not have reconstructive surgery: "Yeah we don't need reconstruction." The surgeon responds by accepting the patient's decision: “Okay, okay” (line 414).

\section{Theme 5: Asserting a preference regarding radiation}

The least prominent theme involved patients explicitly asserting their preferences regarding radiation. This theme emerged in $21 \%$ of all visits (i.e., thematic frequency), and when it emerged, it occurred an average of 2.0 times (i.e., thematic density). The average interactional position of this theme was $53 \%$. This was a selective code that was composed of three axial codes, none of which occurred frequently enough to constitute 'themes' in their own right: (1) Asserting a preference against radiation; (2) Asserting a preference for radiation; and (3) Asserting 'other' preferences regarding radiation. The most prominent of these axial codes was 'asserting a preference against radiation,' which occurred in $9 \%$ of all visits. When it occurred, it did so an average of 2.8 times. The average interactional position of this sub-theme was $50 \%$.

For one example of the sub-theme 'patients asserting a preference against radiation,' see Extract 31. At lines 121-122, the surgeon is describing conditions that are required for 'successful' treatment with lumpectomy (i.e., the removal of only part of the breast), namely the achievement of "negative margins" (i.e., the removal of all cancer 
with no remaining cells left behind), and the post-surgical receipt of "radiation" treatment.

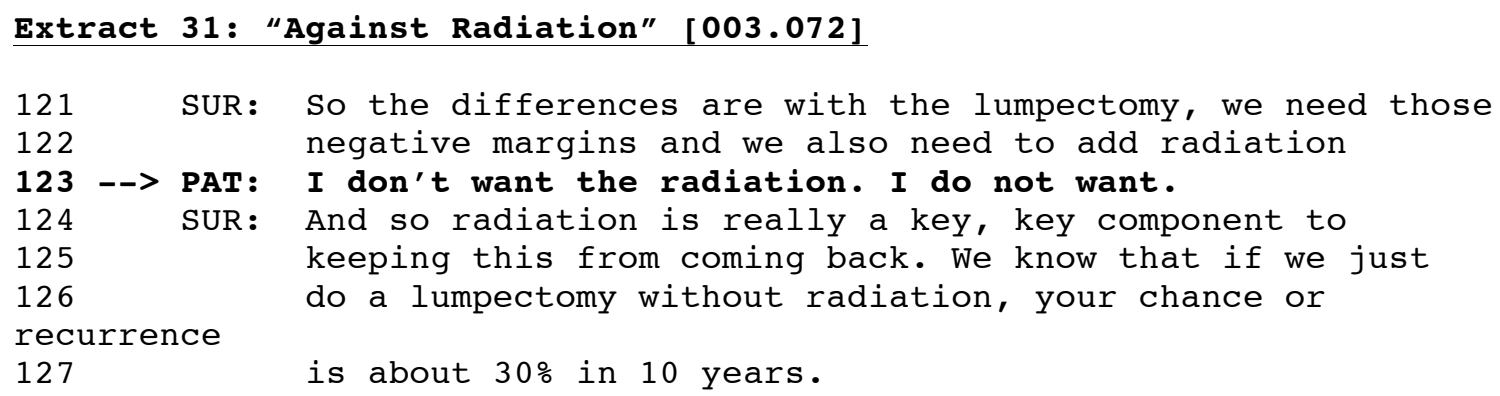

At line 123 , the patient explicitly and emphatically rejects radiation: "I

don't want the radiation. I do not want." The surgeon responds at lines $124-127$ by emphasizing the need for radiation, without which recurrence is " $30 \%$ in 10 years" (line 127). 


\section{Chapter 4: Discussion}

"There is growing recognition throughout the medical and scientific research community that an interdisciplinary approach to cancer prevention and control should incorporate patient-centered communication to maximize the benefit of current medical discovered in diagnosis and treatment - particularly in the emerging era of personalized medicine" (Epstein \& Street, p. X, 2007). For almost a decade, this call for further investigation into patient-centered healthcare has been identified among researchers in the health-communication field, and specifically the field of cancer-patient studies. The data collected for this thesis attempts to contribute to this noted gap in the field. The anxiety and emotional distress that is often paired with a cancer diagnosis (Epstein \& Street, 2007; Robinson et al., 2012) should not be disregarded. Patient-centered cancer care should include an investigative and thorough understanding of what patient's understand 'patient-centered' to be. This understanding will, in part, come from grounded-theoretical explorations of what patients actually talk about.

As a patient-centered healthcare approach begins to become the norm and expected style of care, it becomes increasingly important for researchers, surgeons, and physicians alike to reach a shared understanding of what patients expect their care to be centered on. While it is unlikely that a uniform, or step-by-step, style of patient-centered healthcare will be discovered (largely because every patient is unique with their personal situation and expected healthcare approach), objective and contextualized research within cancer care is crucial to be able to understand what patients naturally make assertions about. 
Epstein and Street's (2007) handbook on Patient-Centered Communication in Cancer Care published by the U.S. Department of Health and Human Services identified the first basic core value of effective communication in cancer care to be "...consider the patients' needs, perspectives, and individual experiences ... provid[ing] patients with opportunities to participate in their care " (p.100), and urges clinicians to "elicit, understand, and validate the patient's perspective and to understand the patient within his or her own psychological and social context" (p.101). The present grounded-qualitative research can help surgeons and clinicians do just that. Through a deeper understanding of clinical experiences of newly diagnosed breast-cancer patients, we can begin to unravel patients' perspectives so that healthcare providers can begin to understand them.

The results of the present thesis offer new information regarding patient agency/assertiveness in breast-cancer patients. The following chapter will discuss how the specific findings of this data can be applied in the field of health communication, specifically to surgeons, to improve communication between breast-cancer patients and surgeons.

Breast cancer is a major threat to women's physical and mental health, and negatively impacts women's quality of life (Siegel et al., 2013; Venetis et al., 2013). This thesis was, in part, motivated by findings suggesting that: (1) the diagnosis of breast cancer is associated with patients' despair and hopelessness, or the belief that "one does not have control over the consequences of one's life ... and the expectation that future events will be negative" (Gidron et al., p. 289, 2001); (2) there is an association between hopelessness and greater disease progression and earlier death from breast cancer (Everson et al., 1996); (3) there is an association between hope and survival from breast 
cancer (Morris et al., 1992); and perhaps most importantly in terms of the study of communication: (4) communicative instantiations of breast-cancer-patients' agency, in the form of patients explicitly asserting their treatment preferences, can indirectly reduce their hopelessness (Robinson et al., 2012).

This thesis was simultaneously motivated by a gap in the literature regarding the theoretical concept of patient agency/assertiveness and its operationalization. Specifically, while patient-advocacy movements and medical education encourage patient agency (Guadagnoli \& Ward, 1998; Nattinger et al., 1996; Nayfield, 1994; Schofield, 2004; Vogel, 2008), and while empirical studies of patient agency almost universally demonstrate its positive effects on health outcomes (Brown et al., 1999; Deci \& Ryan, 1985, 2002; Epstein \& Street, 2011; Pelletier et al., 1997; Ryan, 2000; Ryan et al. 1989; Ryan et al., 1995; Street \& Millay, 2001; Williams \& Deci, 1998), there has been virtually no description (prior to the present thesis) of what the theoretical concept of patient agency means to breast-cancer patients, as evidenced by patients' own communicative behaviors in actual contexts of care.

Guided by a qualitative epistemology and ontology (Silverman, 2011), and specifically a symbolic-interactionist approach (Blumer, 1969), this thesis attempted to answer the following qualitative research question: In the context of surgeons discussing diagnoses and treatment options with recently diagnosed, female-breast-cancer patients, how do patients understand the communicative action of 'asserting treatment preferences?' Using the methods of grounded theory (Blumer, 1969), five specific themes - or, stated differently, five specific content categories of patient assertiveness - were discovered that were robust, insofar as they occurred in at least $20 \%$ of all visits: (1) 
asserting a preference for lumpectomy; (2) asserting a preference for mastectomy; (3) asserting a preference for scheduling surgery as soon as possible; (4) asserting a preference for (more) information; and (5) asserting a preference for reconstructive surgery.

The remainder of this chapter begins by reviewing and discussing the aforementioned five robust themes of patient agency. Although more themes are exemplified above, only the quantitatively robust sub-themes that emerged from this data set will be discussed below, insofar as they occurred in $20 \%$ or more of the data. Following this are recommendations to surgeons for improving their communication with patients.

\section{Asserting a preference for surgical treatment option (lumpectomy vs. mastectomy)}

The majority of women who are diagnosed with breast cancer are clinically eligible for two alternative surgical treatment approaches, including: (1) lumpectomy accompanied by radiation therapy (commonly referred to as 'breast-conserving surgery'); or (2) mastectomy (i.e., removal of an entire breast, which commonly, but not always, obviates the need for radiation). Both treatment options confer an equivalent survival rate for patients without metastatic disease (Fisher et al., 2002; Veronesi et al., 2002). Thus, both alternative procedures are medically justified. Breast-cancer program and policy development considers mastectomy to be over-intrusive and overused (Lantz, Zemencuk, \& Katz, 2002), and considers lumpectomy-with-radiation to be a relatively 'better' treatment outcome. That said, surgical treatment of breast cancer is an instance of preference-sensitive care (Wennberg, 2002). That is, given that patients have differing levels of concern regarding cancer recurrence, radiation therapy, body image, and so 
forth, patients' choice of treatment option is often a matter of personal preference, rather than clinical appropriateness. There are, of course, medical factors that contribute to patients' treatment plan but because more than one treatment option exists, providers need to involve and engage patients in the surgical decision-making process (Frongillo et al., 2013).

Two robust themes emerging from the present data - that is, 'asserting a preference for lumpectomy' and 'asserting a preference for mastectomy' - involved patients asserting preferences regarding surgical treatment options. These themes were not unexpected considering that surgery is an extremely frequent component of treatment of breast cancer, and considering that patients were consulting with surgeons. The theme of patients 'asserting a preference for lumpectomy' occurred in $47 \%$ of all visits and, when it occurred, it did so an average of 3.2 times. By comparison, the theme of patients 'asserting a preference for mastectomy' occurred less frequently in $25 \%$ of all visits and, when it occurred, it did so an average of 2.04 times. Thus, at least in these data, patients appear to advocate relatively more frequently for lumpectomy (vs. mastectomy), bringing them in line with recommendations emerging from breast-cancer programs and policy development (see above). Importantly, though, these data contrast with Frongillo et al.'s (2013) finding that patient's were least involved in conversations relating to lumpectomy (vs. mastectomy), and the present data also contrast with Katz et al.'s (2005) finding that patients' levels of involvement in surgical decision-making were associated with a greater likelihood of patients' receiving mastectomies.

Such contrasts highlight the need to re-examine the ecological validity of the operationalizations of patient agency adopted by Frongillo et al. (2013) and Katz et al. 
(2005). At this time there is no agreed-upon scale or method to measure either shared decision-making or patient involvement (Kasper et al., 2011). Frongillo et al., (2013) operationalized patient involvement in terms of breast-cancer patients' evaluations, on Likert-type scales, of key features of shared decision making (a model borrowed from Charles et al., 1997), including: (1). the presentation of treatment options; (2) a discussion of the risks and benefits of each option; and (3) a discussion of patients' preferences and treatment goals (Frongillo et al., p.70, 2013). This study is similar to others attempting to measure patient-centered care, in that it was conducted using quantitative methods and uses a Likert-type scale. It assumes the data will fit into a presume category and did not examine the data from a grounded theory perspective. Katz (2005) used a similar operationalization.

While previously published research is applicable to the field of patient-centered communication in breast cancer (i.e., it does examine patient involvement from a perspective of patients themselves), it makes particular ontological assumptions (derived from the Likert scales) about what constitutes quality or efficacious patient-centered care. Data of this kind should not be disregarded. However, grounded-qualitative data that examines patient involvement (or agency) from the standpoint of patients, without any predetermined scale or assumed knowledge of participation, has the potential to uncover information on patient-centered health communication that has not yet been considered.

\section{Asserting a preference for scheduling surgery as soon as possible}

One unique aspect of the data uncovered in this thesis that has not been included in measures of patient participation in healthcare is the robust theme that emerged regarding 'scheduling surgery as soon as possible.' While other studies have reported on 
the anxiety, stress, and hopelessness experienced by breast-cancer patients (Epstein \& Street, 2007; Robinson et al., 2012), research has not well explicated particular sources of such anxiety.

A recent study showed that, at least in one study population, the length of time from tissue diagnosis to breast-cancer treatment (i.e., surgery) did not significantly affect women's rates of surviving breast cancer, and that the average wait-time interval from diagnosis to treatment was 43 days (Brazda et al., 2010). Time from diagnosis to treatment (i.e., surgery) has significantly increased over time; patients treated in 1998 waited an average of 21.8 days for surgery, while patients treated in 2003 waited 31.3 days and patients treated in 2008 waited 41.1 days (Hulvat, Sandalow, Rademaker, Henelowsi, Hansen, 2010), bringing them into line with the 43-day wait-time average reported by Brazda et al. (2010). One key reason why the average diagnosis-to-surgery wait-time interval has increased is that woman are increasingly being actively encouraged to make considered, informed decisions about their treatment, including seeking second opinions. Surgeons justify such encouragement - and did so in the present data - by telling patients about study (Brazda et al., 2010) suggesting that patients can wait up to 90 days between tissue diagnosis and breast-cancer treatment (i.e., surgery) without risks to survival.

These 'medical facts' appear to provide very little solace to the patients in the present data. Remember that these patients were diagnosed an average of 7 days prior to their consultations with surgeons, and the theme of patients 'asserting a preference for scheduling surgery as soon as possible' occurred in $40 \%$ of all visits and, when it occurred, it did so an average of 1.6 times. This is a completely novel finding. In sum, 
regardless of the 'medical facts,' patients want surgery 'now,' and patients' desire to 'get it over with' likely contributes to their extremely high levels of pre-treatment anxiety (Tsianaks, et al., 2012).

One widely agreed upon feature of patient-centered care is that healthcare providers should "address the patient's perspective, understand the patient within his or her psychosocial context" (McCormack et al., p. 1086, 2011). Similarly, patient-centered care centrally involves listening to patients and their preferences (De Boer, Delnoij, \& Rademakers, 2013; McCormack et al., 2011; Epstein \& Street, 2007). Somehow surgeons need to find ways to address patients' strong concerns regarding 'scheduling surgery as soon as possible.' Some questions are: Does surgeons' encouraging patients to 'delay surgery' in order to make thorough treatment decisions - for example, to get more information, to get second surgical opinions, or to talk with spouses, friends, and family members - make patients more or less anxious, and is such encouragement effective given patients' strong preferences for moving quickly to surgery? If surgeons address this specific anxiety in patient assertiveness, by explaining or defining a specific treatment plan, does it change anxiety or stress levels among patients? Asserting a preference for (more) information

In cancer contexts generally, and in the specific context of breast cancer, one of patients' primary goals is acquiring medical information (for a review, see Rutten, Arora, Bakos, Aziz, \& Rowland, 2005). Approximately 90\% of cancer patients report wanting all/full information about their cancer (for a review, see Roberts, Cox, Reintgen, Baile, \& Gibertini, 1994; Ong et al., 1999), approximately 75\% report wanting 'as many details as possible' (Ong et al., 1999), and cancer-patients' chief reason for seeking second 
opinions is to gain more detailed information (Tattersall et al., 2009). Specific types of information that patients desire vary dramatically, including that about cancer itself, likelihood of cure, treatment options, needed tests, the physical and affective sides effects of treatment, and prognosis (Harrison et al., 1999; Tsianaks et al., 2012).

Relevant to the present data, in which patients averaged 60.5 years of age, researchers have found that older (vs. younger) breast-cancer patients desire less information and are more satisfied with the information they receive (Harrison et al., 1999). When breast-cancer patients are given more (vs. less) information, they feel more confident in making their own decisions and asserting treatment preferences (Harder et al., 2013). Tailoring information to the specific needs of cancer patients has been shown to decrease patients' emotional distress, enhance their ability to care for themselves, and improve their ability to continue their usual activities (Harrison et al., 1999).

In line with prior literature, the theme of 'asserting a preference for (more) information' emerged in $31 \%$ of all visits and, when it emerged, occurred an average of 1.8 times. No particular type of information emerged as 'thematic,' per se, with patients asserting preferences for information about pathology, diagnosis, prognosis, genetics, medication, and so on. Surgeons need to (continue to) make efforts to provide patients with enough consultation time to receive and solicit sufficient information, and to ensure information comprehension and retention.

Asserting a preference for reconstructive surgery

Breast reconstruction - that is, an additional surgical procedure on the breast that is typically performed by a plastic surgeon - is a relevant option for both of the major types of treatment of breast cancer, including lumpectomy and mastectomy. In the case of 
breast cancer, reconstruction is fully covered by health insurance under federal law. Women who receive reconstruction after mastectomy (vs. those that do not) have improved psychological, social, and emotional health (Chen et al., 2009). Despite these facts, data suggest that relatively few women receive reconstruction. For example, only $38 \%$ of post-mastectomy women received breast reconstruction in 2001-2003 (Chen et al., 2009).

While reconstructive surgery may not be the first topic of concern or conversation that immediately comes to mind in regards to a breast-cancer diagnosis, it is a prevalent piece of the puzzle. Considering that the present data involved surgeons and breastcancer patients, reconstruction was a topic that inevitably occurred in most, if not all, transcripts used for this thesis. The theme of patients 'asserting a preference for reconstructive surgery' occurred in $30 \%$ of all visits and, when it occurred, did so an average of 1.6 times. This was so amid the relatively older population of patients examined in this thesis, even though Chen et al., (2009) found that younger (vs. older) patients are more likely to receive breast reconstruction.

\section{Summarizing recommendations to surgeons}

According to the American Society of Clinical Oncology (1998) and the National Academy of Sciences' Institute of Medicine (2001), patient-clinician communication is a key clinical skill and a cornerstone of comprehensive cancer care. A key question is: What are specific and trainable communication behaviors that matter for particular psychosocial health outcomes?

The findings of the present thesis are most relevant to surgeons. According to self-determination theory, patient agency occurs when patients are motivated, of their 
own volition, to speak-up for themselves. Surgeons can be instrumental in supporting or encouraging patients' agency, for example by listening carefully to patients' perspectives, providing relevant information, offering choices about treatment regimes, supporting patients' initiatives, and minimizing control (Williams \& Deci, 1995; Williams, Deci, \& Ryan, 1995;Williams et al. 1991). Insofar as breast-cancer patients asserting treatment preferences is directly associated with increasing patients' satisfaction with surgeons, and indirectly associated with decreases in patients' hopelessness, surgeons should be interested in knowing exactly what types of treatment preferences are salient and important to patients. With this information, surgeons should be able to tailor their communication so as to more efficiently address patients' preferences.

In this regard, prior literature has not provided surgeons with much of a roadmap, and this is exacerbated by the fact that surgeons and oncologists are lacking in communication competence (Girgis, Sanson-Fisher, \& Walsh, p. 73, 2000). Wittmann et al. (2011) studied the information needs of patients diagnosed with oesophageal and gastric cancer, and found large gaps between patients' desires and surgeons perceptions. While information, recommendations, and suggestions on how/why patients can/should become better self advocates, and on how/why patients' companions can/should become better advocates for patients, surgeons are not being offered the same information and medical training. Extensive research - starting in the 1990's when patient advocacy publically emerged and became acceptable (see chapter 1) - demonstrates that patients benefit when practitioners are more interactive and provide patients more information (Hall, Roter, \& Katz, 1988; Roberts et al., 2009; Schain, 1990). In line with this, the American Society of Clinical Oncology (ASCO, 1998) and the Institute of Medicine 
(IOM, 2001) report that communication is a key clinical skill. While patient-centered communication can reduce anxiety, improve the likelihood that patients will engage in therapeutic relationships, and increase patients' satisfaction (Bylund et al., 2009), surgeons receive little training on how to be patient centered. Similarly, while surgeons and oncologists are provided with information that 'good communication' is important for example, to reduce litigation regarding malpractice - and while surgeons and oncologists are given very general information regarding the types of communication that patients reportedly prefer (e.g., 'more interactivity,' or 'better listening'), there is virtually no research, quantitative or qualitative, examining the actual communication practices between surgeons and patients (Levinson, Hudak, \& Tricco, 2013; for an exception, see Robinson et al., 2012). In sum, as reviewed by Epstein and Street (2007): "few guidelines exist to help clinicians an health care systems communicate effectively with patients who have cancer" (p.1).

Although there is a wealth of data on actual communication styles of primary-care physicians, it is not at all clear that these results apply to the very different context of oncology, let alone oncological-surgery specifically (Levinson et al., 2013; Rao, Anderoson, Inui, \& Frankel, 2007). A review of the communication styles of surgeons found that they talk dramatically more than primary-care physicians, offer many more surgical recommendations, and adopt a more biomedical (vs. psychosocial) style (Levinson \& Chaumeton, 1999). Additionally, research suggests that surgical contexts are more infused with asymmetrical power dynamics (Mirivel, 2008; Phillips, 1996). The data found in the present thesis offers recommendations for what topics surgeons should 
address, or at the very least should be prepared to deal with, when interacting with breastcancer patients.

Aside from Chen et al.'s (2009) finding that as many as $81 \%$ of breast-cancer patients discuss reconstruction with surgeons, perhaps the largest repository of advice that surgeons might consult regarding patient agency is merely vernacular (i.e., not empirically verified), coming from websites of nonprofit organizations. For example, the website of Inside Out recommends that breast-cancer patients: (1) Learn the basics of the disease; (2) Inquire about treatment options; (3) Create a list of questions; (4) Seek second opinions; (5) Share everything with physicians; (6) Always keep a current list of medications; and (7) Keep an organized file (Medical Advocacy, n.d.). Similar types of advise can be found on websites of the National Cancer Institute (http://www.cancer.gov/), the Komen foundation (http://ww5.komen.org/), the American Cancer Society (http://www.cancer.org), and The National Coalition for Cancer Survivorship (http://www.canceradvocacy.org/cancer-advocacy/what-is-advocacy/). There is also information - again vernacular -that comes from support groups in breastcancer patients (Goodwin, 2005; Waller \& Batt, 1995).

This thesis uncovered five central content domains of patient agency that are salient to patients: (1) asserting a preference for lumpectomy; (2) asserting a preference for mastectomy; (3) asserting a preference for scheduling surgery as soon as possible; (4) asserting a preference for (more) information; and (5) asserting a preference for reconstructive surgery. Note that some themes are, perhaps counter-intuitively, absent from this list. Take, for example, the topic of radiation. Although radiation is clinically recommended as a follow-up treatment to lumpectomy (reducing the average chance of 
recurrence from $50 \%$ to $2 \%$; Chen et al., 2009), it is also sometimes recommended as a follow-up treatment to mastectomy (because removing the entire breast does not always ensure that cancer has not spread to the chest muscle, which is not removed with mastectomy). Given that women commonly report a fear of radiation, which is associated with reduced screening (Consedine, Magai, \& Neugut, 2004), it is perhaps surprising but perhaps relieving to surgeons - that patients in the current data did not commonly assert a 'preference against radiation' (occurring in only 9\% of all visits).

\section{Thematic Density}

The thematic density of each quantitatively robust theme and sub-theme was calculated in this data. As previously mentioned, this data was examined using a grounded-theoretical approach. This means that researchers did not know which codes or themes would emerge or become significant. As data coding ensued, it became evident that some utterances were asserted multiple times. The number of times each assertive utterance occurred initially suggested a potentially robust finding. As research concluded, however, this did not prove to be the case. However, the density findings for each subtheme still provide some interesting findings. Of the five themes that eventually became quantitatively robust, the following three themes had a density of over two: surgical decisions, scheduling surgery, and radiation. Given that, in the larger data set, patients asserted treatment preferences an average of seven times per visit, a density rating of over two suggests that the theme constituted almost $30 \%$ of all assertions. Surgeons and other health-communication scholars may want to focus more of their attention on assertive utterances that relate to surgical decisions, scheduling surgery, and radiation.

\section{Interactional Position}


The average interactional position of each quantitatively robust theme and subtheme was also calculated in this thesis. Although the point at which each assertive utterance occurs could potentially provide more information for surgeons and health care practitioners, the results of these codes in this study became relatively unremarkable. The range of the average interactional position was $49 \%$ - $60 \%$, or about midway through conversation (with the exception of one outlier, discussed below). This positioning is to be expected, given that this is during the 'middle' of surgeons' explanations of surgery and other treatment options, including radiation, reconstruction, etc. The one notable finding involved the theme of scheduling surgery. For this theme, patients asserted their preferences an average of $76 \%$ of the way through consultations, that is, after surgeons had effectively completed their relatively 'standardized' explanations of treatment options. During these explanations, surgeons do not tend to address matters of scheduling. Despite the fact that surgeons may be unable to formulate treatment schedules until later on in consultations - that is, after patients have decided on courses of treatment - surgeons could allay patients' anxiety by introducing the topic of scheduling earlier in consultations. Surgeons could, for example, tell patients at the beginning of consultations that scheduling will be discussing after other issues are considered.

\section{Limitations}

This study offers surgeons and other healthcare professionals an abundance of qualitatively robust findings that are potentially beneficial in regards to improving physician-patient communication. However, the conclusions reached as a result of this data are not without limitations. First, findings are not generalizable beyond the present sample. The women in this study were $94.6 \%$ White, non-Hispanic; $62.2 \%$ of patients 
had at least an undergraduate degree; $62.8 \%$ of participants were married; $57 \%$ of participants reported a household income of $\$ 60,000$ or more; and $83.8 \%$ of participants brought companions to their consultations. Findings may not apply to men, or to more culturally or socioeconomically diverse populations. Findings may not apply to patients diagnosed with other types of cancer, to patients being treated for other ailments, or to patients who have been diagnosed with breast cancer in the past.

Second, the analysis focused solely on patients' assertive utterances, and other factors may have played a role in whether or not such utterances were 'effective,' such as surgeons' responses to patients' assertive utterances. For example, surgeons often agreed with, and supported, patients' assertive utterances, but sometimes surgeons disagreed with, and resisted, them. For an example of a surgeon agreeing with, and supporting, a patient's assertive utterance, see example 32 (below). Here, the nurse is explaining the side effects of a medication that may be prescribed to this patient. During the conversation, acupuncture, as an alternative therapy arises in the conversation.

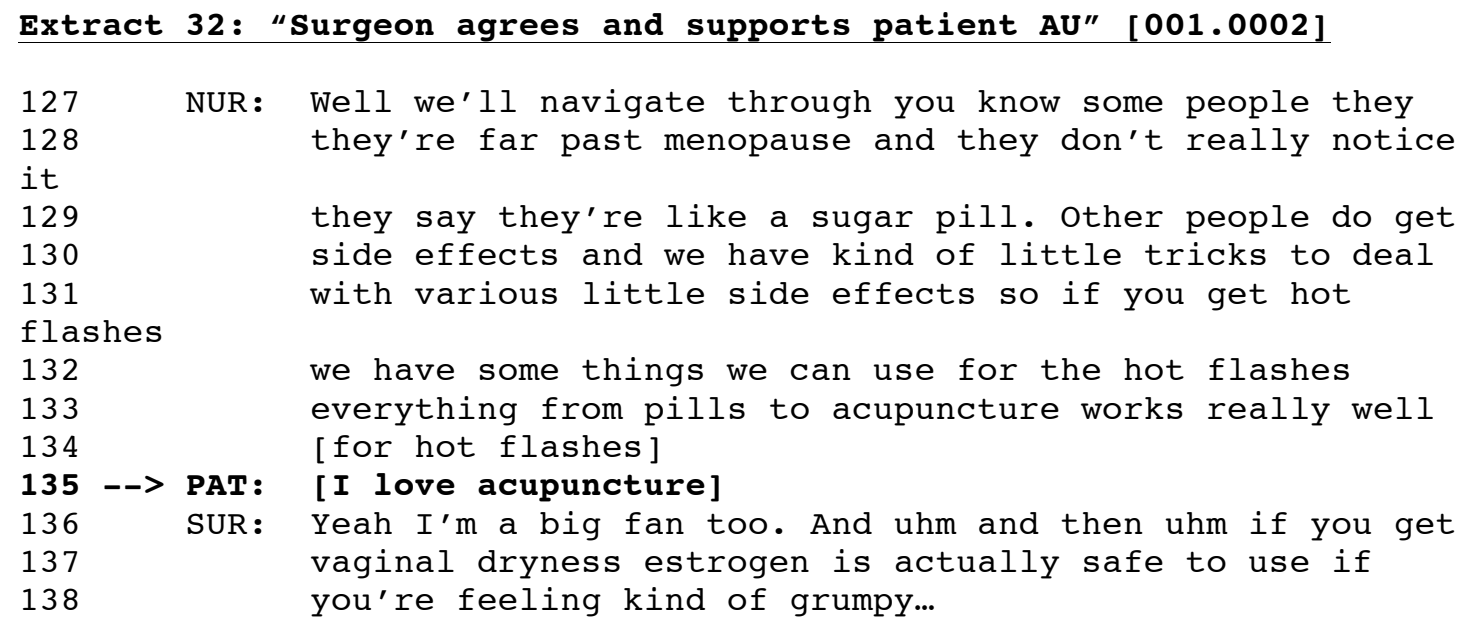


At line 135, the patient asserts her preference for acupuncture by positively evaluating it, "I love acupuncture," and the surgeon agrees and supports this position by responding with: "Yeah I'm a big fan too."

For an example of a surgeon rejecting a patient's assertive utterance, see example 33 (below). Here, the surgeon is explaining the importance of this patient going to see a radiation oncologist. In this excerpt, the surgeon has already made it very clear that the patient can decline radiation if she desires, but that she should 'get all the facts' regarding radiation and how it might influence her treatment in advance of decision making.

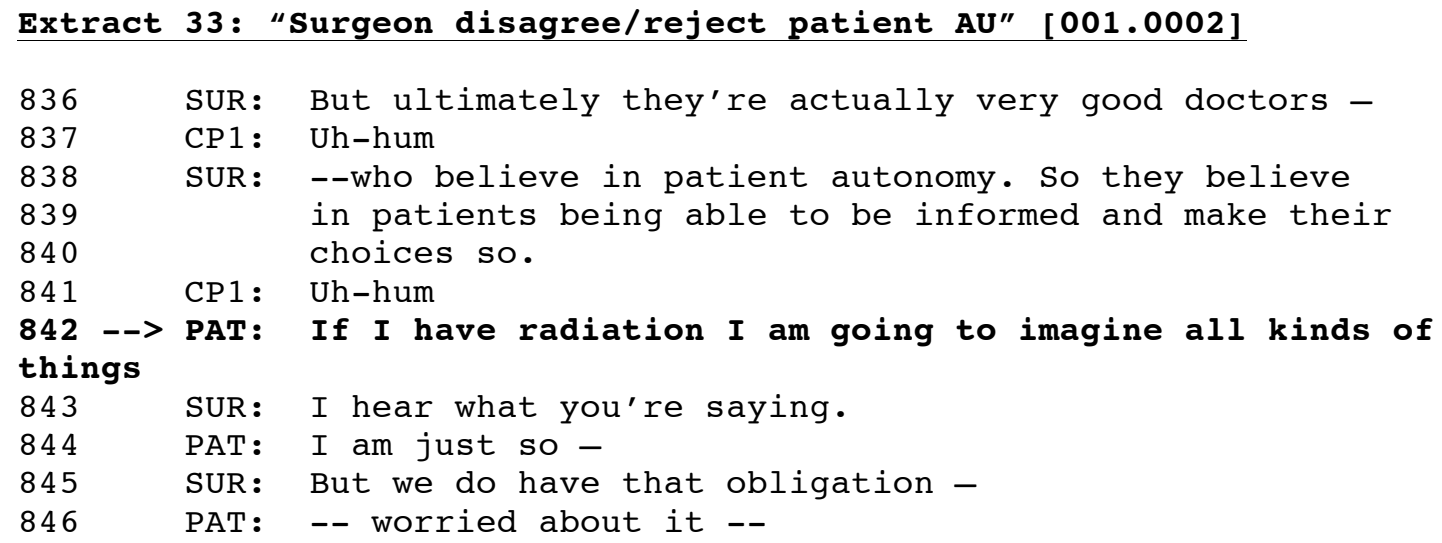

At line 842 , the patient resists radiation by asserting her negative reaction to it.

Although the surgeon nominally accepts the patient's position, "I hear what you're saying" (line 843), the surgeon disagrees with the patient's position: "But we do have that obligation" (line 845).

Third, this study only focused on patients themselves, not their companions.

\section{Future Directions}

This study provided insight into a sub-field of patient-centered health care that we know very little about; That is, prior research has provided very little guidance in terms of what breast-cancer patients actually advocate for. However, this study only 
'scratches the surface' of this domain, and much more research is necessary. First, this study should be replicated with a larger, more diverse sample. Second, as noted above, in addition to patients' assertive utterances, other factors need to be simultaneously considered. For example, were patients' assertive utterances strongly solicited by surgeons (e.g., were patients responding to the surgeon's questions, such as "What do you prefer?"), or were patients' assertive utterances strongly self-initiated, and how might this affect the concept of patient agency? Answers to this question will help us refine our notion of shared decision making. Or again, how did surgeons respond to patients' assertive utterances, and how might this affect the concept of patient agency? Future research also needs to investigate patients' companions' roles in patient agency, including the types of things that companions are advocating for, and how companions' assertiveness affects patients' assertiveness.

Finally, if the present findings are replicated and validated, then future research needs to begin to 'fold them into' the development of future quantitative analyses of patient agency, at least in terms of questionnaires/surveys used to measure patient agency. According the present results, measures of patient agency (or perhaps patients' preferences in terms of agency) should include questions pertaining to patients' preferences for lumpectomy versus mastectomy surgeries, for information related to treatment, for surgical reconstruction, and finally for scheduling. 


\section{References}

American Cancer Society. n.d. Retrieved on October 15, 2014. http://www.cancer.org/

American Society of Clinical Oncology (1998). Cancer care during the last phase of life. Journal of Clinical Oncology, 16, 1986-1996.

Beisecker, A. E., \& Beisecker, T. D. (1990). Patient information-seeking behaviors when communicating with doctors. Medical Care, 28,1, 19-28.

Bensing, J. (2000). Bridging the gap.: The separate worlds of evidence-based medicine and patient-centered medicine. Patient Education and Counseling, 39,1, 17-25. doi:10.1016/S0738-3991(99)00087-7

Blumer, H. (1969). Symbolic interactionism; perspective and method. Englewood Cliffs, N.J.: Prentice-Hall.

Brashers, D. E., Haas, S., \& Neidig, J. (1999). The patient self-advocacy scale: measuring patient involvement in health care decision-making interactions. Health Communication, 11,(2), 97-121.

Braun, S. (2003). The History of Breast Cancer Advocacy. The Breast Journal, 9, S101S103.doi: 10.1046/j.1524-4741.9.s2.13.x

Brazda, A., Estroff, J., Euhus, D., Leitch, A. M., Hutch, J., Andrews, V., Moldrem, A., Rao, R. (2010). Delays in time to treatment and survival impact in breast cancer. Annals of Surgical Oncology, 17(3), 291-296.

Brinker, N. (2011). Betty Ford brought breast cancer out into the open. CNN Opinion. (http://www.cnn.com/2011/OPINION/07/12/brinker.betty.ford/

Brown, R., Butow, P. N., Boyer, M. J., \& Tattersall, M. H. (1999). Promoting patient participation in the cancer consultation: evaluation of a prompt sheet and coaching in question-asking. British Journal of Cancer, 80(1-2), 242-248. doi:10.1038/sj.bjc. 6690346

Bruera, E., Willey, J. S., Palmer, J. L., \& Rosales, M. (2002). Treatment decisions for breast carcinoma : Patient preferences and physician perceptions. CNCR Cancer, 94(7), 2076-2080.

Buchanan, A. (1978). Medicalpaternalism. Philosophy and Public Affairs, 7(4), 370-390.

Bylund, C. L., Brown, R., Geuguen, J. A., Diamon, C,. Bianculli, J., \& Kissane, D. W. (2009). The Implementation and assessment of a comprehensive communication skills training curriculum for oncologists. Psycho-Oncology, 19(6), 583-593. 
Charles, C., Gafni, A., \& Whelan, T. (1997). Shared decision-making in the medical encounter: what does it mean? (or it takes a least two to tango) Social Science \& Medicine., 44(5), 681-692

Charles C, Whelan,T., \& Gafni A,. (1999). What do we mean by partnership in making decisions about treatment? BMJ: British Medical Journal. 319(7212), 780-782.

Chen, J., Malin, J., Ganz, P., Ko, C., Tisnado, D., Tao, M.... \& Kahn, K. (2009). Variation in physician-patient discussion of breast reconstruction. Journal of General Internal Medicine, 24(1), 99-104.

Committee on Quality of Health Care in America, Institute of Medicine (2001). Crossing the Quality Chasm: A New Health System for the 21st Century. Washington, DC: National Academies Press.

Consedine, N. S., Magai, C., \& Neugut, A. L. (2004). The contribution of emotional characteristics to breast cancer screening among women from six ethnic groups. Preventive Medicine, 38(1), 64-77.

Cortes, D.E., Mulvaney-Day, N., Fortuna, L, Reinfeld, S., \& Alegría M. (2009). Patient-provider communication: understanding the role of patient activation for Latinos in mental health treatment. Health Education and Behavior. 36(1), 138-154.

Davidson, I. (N.A.) Betty Ford: Courageous Pioneer. http://www.idelledavidson.com/articles/pp_bford.html

Deber, R. B., Kraetschmer, N., Urowitz, S., \& Sharpe, N. (2007). Do people want to be autonomous patients? Preferred roles in treatment decision-making in several patient populations. Health Expectations, 10(3), 248-258. doi:10.1111/j.13697625.2007.00441.x

De Boer, D., Delnoij, D., Rademakers, J. (2013). The importance of patient-centered care for various patient groups. Patient Education and Counseling, 90(3), 405-406.

Deci, E. L., \& Ryan, R. M. (1985). Intrinsic motivation and self-determination in human behavior. New York: Plenum.

Deci, E. L., \& Ryan, R.M. (2002). Handbook of self-determination research. Rochester, NY: University of Rochester Press.

Epstein R. M., \& Street R. L. (2007) Patient-Centered Communication in Cancer Care: Promoting Healing and Reducing Suffering. National Cancer Institute, NIH Publication 7(6225). Bethesda, MD. 
Epstein R. M., \& Street, R.L J. (2011). Shared mind: communication, decision making, and autonomy in serious illness. Annals of Family Medicine, 9,5, 454-461

Everson, S. A., Goldberg, D. E., Kaplan, G. A., Cohen, R. D., Pukkala, E., Tuomilehto, J., \& Salonen, J. T. (1996). Hopelessness and risk of mortality and incidence of myocardial infarction and cancer. Psychosomatic Medicine, 58(2), 113-121

Fisher, B., Anderson, S., Bryant, J., Margolese, R. G., Deutsch, M., Fisher, E. R., ... Wolmark, N. (2002). Twenty-year follow-up of a randomized trial comparing total mastectomy, lumpectomy, and lumpectomy plus irradiation for the treatment of invasive breast cancer. New England Journal of Medicine, 347, 1233-1241

Fraenkel, L., \& McGraw, S. (2007). Participation in medical decision making: the patients' perspective. Medical Decision Making, 27(5), 518-519.

Frongillo, M., Feibelmann, S., Belkora, J., Lee, C., Sepucha, K. (2013). Is there shared decision making when the provider makes a recommendation? Patietn Education and Counseling, 90(1), 69-73.

Lantz, P. M., Zemencuk, J. K., \& Katz, S. J. (2002). Is mastectomy overused? A call for expanded research project. Health Services Research, 37, 417-431. doi: $10.1111 / 1475-6773.030$

Gidron, Y., Magen, R., \& Ariad, S. (2001). The Relation between hopelessness and psychological and serological outcomes in Israeli women with breast-cancer. Psychology and Health, 16(3), 289-296.

Girgis, A., Sanson-Fisher, R. W., \& Walsh, R. (2001). Preventive and other interactional skills of general practitioners, surgeons, and physicians: Perceived competence and endorsement of postgraduate training. Preventive Medicine, 32(1), 73-81.

Glaser, B. G., \& Strauss, A. L. (1967). The discovery of grounded theory: strategies for qualitative research. Hawthorne, N.Y.: Aldine de Gruyter.

Goodwin, P. J. (2005). Support groups in advanced breast cancer. Cancer, 104(S11), 2596-2601.

Guadagnoli, E., \& Ward, P. (1998). Patient participation in decision-making. Social Science and Medicine, 47(3), 329-339. doi:10.1016/S0277-9536(98)00059-8

Hack, T. F., Degner, L. F., \& Dyck, D. G. (1994). Relationship between preferences for decisional control and illness information among women with breast cancer: A quantitative and qualitative analysis. Social Science and Medicine Social Science and Medicine, 39(2), 279-289. 
Hack, T. F., Degner, L. F., \& Parker, P. A. (2005). The communication goals and needs of cancer patients: a review. Psycho-Oncology, 14(10), 831-845.

doi:10.1002/pon.949

Hack, T. F., Degner, L. F., Watson, P,. \& Sinha, L. (2005). Do patients benefit from participating in medical decision making? Longitudinal follow-up of women with breast cancer. Psycho-Oncology, 15(1), 9-19.

Hall, J. A., Roter D. L., \& Katz, N. R. (1988). Meta-analysis of correlates of provider behavior in medical encounters. Medical Care. 26(7), 657-675

Handbook of self-determination research. (2002). Rochester, NY: University of Rochester Press.

Harder, H., Ballinger, R., Langridge, C., Ring, A., \& Fallowfield, L. J. (2013). Adjuvant chemotherapy in elderly women with breast cancer: Patients' perspectives on information giving and decision making. Psycho-Oncology. 22(12), 2729-2735.

Harrison, D. E., Galloway, S., Graydon, J. E., Palmer-Wickham, S., \& Rich-van der Bij, L. (1999). Information needs and preferences for information of women with breast cancer over a first course of radiation therapy. Patient Education and Counseling. 38(3), 217-255.

Hulvat, M., Sandalow, N., Rademaker, A., Helenowski, I., Hansen, N. M. (2010). Time from diagnosis to definitive operative treatment of operable breast cancer in the era of multimodal imaging. Surgery, 148(4), 746-751.

Hwang, S. (2008). Utilizing qualitative data analysis software. Social Science Computer Review, 26(4), 519-527.

Joosten, E. A. G., DeFuentes-Merillas, L., De-Weert, G. H., Sensky, T., Van Der Staak, C. P.F., \& De Jonh, C. A. J. (2008). Systematic review of the effects of shared decision-making on patient satisfaction, treatment adherence and health status. Psychotherapy and Psychosomatics, 77(4), 219-226.

Kasper, J., Heesen, C., Köpke, S,. Fulcher, G., \& Geiger, F. (2011). Patients' and observers' perceptions of involvement may differ. Validation study on interrelating measures for shared decision making. PLoS ONE, 6(10), 262-265.

Katz, S. J., Lantz, P. M., Janz, N. K., Fagerlin, A., Schwartz, K., Liu, L... \& Morrow, M. (2005). Patient involvement in surgery treatment decisions for breast cancer. American Society of Clinical Oncology, 23(24), 5526-55233.

Kraetschmer, N., Sharpe, N., Urowitz, S., \& Deber, R. B. (2004). How does trust affect 
patient preferences for participation in decision-making? Health Expectations, 7(4), 317-326.

Lane, D. S., Polednak, A. P., \& Burg, M.A. (1989). The impact of media coverage of Nancy Reagan's experience on breast cancer screening. American Journal of Public Health. 79(11), p. 1551-1552. doi: 10.2105/AJPH.79.11.1551)

Lantz, P. M., Zemencuk, J. K., \& Katz, S. J. (2002). Is mastectomy overused? A call for expanded research project. Health Services Research, 37, 417-431. doi: $10.1111 / 1475-6773.030$

Levinson, W., Chaumeton, N. (1999). Communication between surgeons and patients in routine office visits. Surgery. 125(2), 127-134.

Levinson, W., Hudak, P., Tricco, A. C. (2013). A systematic review of surgeon-patient communication: Strengths and opportunities for improvement. Patient Education and Counseling, 93(1), 3-17.

McCormack, L. A., Treiman, K., Rubert, D., Williams-Piehota, P., Nadler, E., Arora, N. K., ... Street, R. L. (2011). Measuring patient-centered communication in cancer care: A literature review and the development of a systematic approach. Social Science and Medicine. 72(7), 1085-1095.

McKinstry, B. (1992). Paternalism and the doctor-patient relationship in general practice. The British Journal of General Practice: The Journal of the Royal College of General Practitioners, 42(361), 340-2.

Medical Advocacy, How to be an advocate for yourself or a loved one. Retrieved October 15, 2014. https://www.side-out.org/about-side-out/

Mirivel, J. C. (2008). The physical examination in cosmetic surgery: Communication strategies to promote the desirability of surgery. Health Communication, 23(2), 153-170.

Morris, T., Pettingale, K., \& Haybittle, J. (1992). Psychological response to cancer diagnosis and disease outcome in patients with breast cancer and lymphoma. Psycho-oncology, 1(2), 105-114

Miller, L. L. H., Miller, J., \& Joanne, E. (2006). What is patient advocacy? Benefits and Compensation Digest, 43(12), 24-29.

National Coalition for Cancer Survivorship. n.d. Retreived on October 19, 2014. http://www.canceradvocacy.org/cancer-advocacy/what-is-advocacy/

National Cancer Institute. n.d. Retreived October 11, 2014. http://www.cancer.gov/. 
Nattinger, A. B., Hoffmann, R. G., Shapiro, R., Gottlieb, M. S., \& Goodwin, J. S. (1996). The effect of legislative requirements on the use of breast-conserving surgery. New England Journal of Medicine, 335(14), 1035-1041. doi:10.1056/NEJM199610033351407

Nayfield, S. G., Bongiovanni, G. C., Alciati, M. H., Fischer, R. A, \& Bergner, L. (1994). Statutory requirements for disclosure of breast cancer treatment alternatives. Journal of the National Cancer Institute, 86(16), 1202-1208.

Ong, L. M. L., Visser, M. R. M., Van Zuuren, F. J., Rietbroek, R. C., Lammes, F. B., \& de Haes, J. C. J. M. (1999). Cancer patients' coping styles and doctor-patient communication. Psycho-Oncology, 8, 155-166

Pelletier, L. G., Tuson, K. M., \& Haddad, N. K. (1997). Client motivation for therapy scale: A measure of intrinsic motivation, extrinsic motivation, and amotivation for therapy. Journal of Personality Assessment, 68(2), 414-35.

Phillips, D. (1996). Medical professional dominance and client dissatisfaction: A study of doctor-patient interaction and reported dissatisfaction with medical care among female patients at four hospitals in Trinidad and Tobago. Social Science and Medicine, 42(10), 1419-1425.

Psychological Response to Cancer Diagnosis and Disease Outcome in Patients with Breast Cancer and Lymphoma. (1992). Psycho-Oncology, 1(2), 105-114.

Rao, J. K., Anderson, L.A., Inui, T. S., Frankel, R. M. (2007). Communication interventions make a difference in conversations between physicians and patients: a systematic review of the evidence. Medical Care, 45(4), 340-349

Robinson, J., Hoover, D., Venetis, M., Kearney, T., \& Street, R. (2012). Consultations between patients with breast cancer and surgeons: a pathway from patientcentered communication to reduced hopelessness. Journal of Clinical Oncology, 31(3), 351-358.

Roberts, C. S., Cox, C. E., Reintgen, D. S., Baile, W. F., Gibertini, M. (2009). Influence of physician communication on newly diagnosed breast patients psychologic adjustment and decision-making. Cancer, 74(S1), 336-341.

Roter, D. L. (1977). Patient participation in the patient-provider interaction: the effects of patient question asking on the quality of interaction, satisfaction and compliance. Health Education Monographs, 5(4), 281-315.

Royal, L. E. (2011). Become an empowered patient: here's how to actively manage your 
healthcare and speak up for your rights when you're ill. Black Enterprise, 4,(7), $88-92$.

Rutten, L. J., Arora, N. K., Bakos, A. D., Aziz, N., \& Rowland, J. (2005). Information needs and sources of information among cancer patients: A systematic review of research (1980 2003). Patient Education \& Counseling, 57, 250-261. doi: 10.1016/j.pec.2004.06.006

Ryan, R. M., \& Connell, J. P. (1989). Perceived locus of causality and internalization: examining reasons for acting in two domains. Journal of Personality and Social Psychology, 57(5), 749-61.

Ryan, R. M., \& Deci, E. L. (2000). Self-determination theory and the facilitation of intrinsic motivation, social development, and well-being. The American Psychologist, 55(1), 68-78.

Ryan, R. M., Plant, R. W., O’Malley, S. (1995). Initial motivations for alcohol treatment: relations with patient characteristics, treatment involvement, and dropout. Addictive Behaviors, 20(3), 279-297.

Schain, W.S. (1990) Physician-patient communication about breast cancer: a challenge for the 1990s. The Surgical Clinics of North America, 70(4), 917-936.

Schofield, P. E., \& Butow, P. N. (2004). Towards better communication in cancer care: a framework for developing evidence-based interventions. Patient Education and Counseling Patient Education and Counseling, 55(1), 32-39.

Siegel, R., Naishadham, D., \& Jemal, A. (2013). Cancer statistics, 2013. CA: A Cancer Journal for Clinicians, 63(1), 11-30. doi:10.3322/caac.21166

Silverman, D. (2011). Interpreting qualitative data: a guide to the principles of qualitative research. London; Thousand Oaks, Calif.: SAGE Publications.

Silverman, E., Woloshin, S., Schwartz, L. M., Byram, S. J., Welch, H. G., \& Fischhoff, B. (2001). Women's views on breast cancer risk and screening mammography: A qualitative interview study. Medical Decision Making, 21(3), 231-240.

Strauss, A. L., and Corbin, J. M. (1998). Basics of qualitative research: techniques and procedures for developing grounded theory. Thousand Oaks: Sage Publications.

Street, R. L. (1992). Communicative styles and adaptations in physician-patient consultations. Social Science \& Medicine, 34(10), 1155-1163.

Street, R. L.\& Millay, B. (2001). Analyzing patient participation in medical encounters. 
Health Communication, 13(1), 61-73.

Street, R. L., Gordon, H. S., Edward, K., Richard, K. (2005). Patient participation in medical consultations: Why some patients are more involved than others. Medical Care, 43(10), 960-969.

Street, R. L., \& Voigt, B. (1997). Patient participation in deciding breast cancer treatment and subsequent quality of life. Medical Decision Making. 17(3), 298-306.

Susan G. Komen ${ }^{\circledR} \mid$ About Us | Susan G. Komen's Story | Susan G. Komen’s Story. (n.d.). Retrieved February 26, 2014, from http://ww5.komen.org/AboutUs/SusanGKomensStory.html

Tattersall, M. H. N., Dear, R. F., Jansen, J., Shepherd, H. L., Devine, R. J., Horvath, L. G., ...Boyer, M. J. (2009). Second opinions in oncology: The experiences of patients attending the Sydney Cancer Centre. The Medical Journal of Australia, 191, 209-212.

Tsianakas, V., Robert, G., Maben, J., Richardson, A., Dale, C., Wiseman, T. (2012). Implementing patient-centered cancer care: using experience based co-design to improve patient experiences in breast and lung cancer services. Supportive Care in Cancer. 20(11), 2639-2647.

Venetis, M. K., Robinson, J. D., Turkiewicz, K. L., \& Allen, M. (2009). An evidence base for patient-centered cancer care: A meta-analysis of studies of observed communication between cancer specialists and their patients. Patient Education and Counseling, 77(3), 379-383.

Venetis, M. K., Robinson, J. D., \& Kearney, T. (2013). Consulting with a surgeon before breast cancer surgery: Patient question asking and satisfaction. Journal of Health Communication, 18(8), 943-959. doi:10.1080/10810730.2012.757391

Veronesi, U., Cascinelli, N., Mariani, L., Greco, M., Saccozi, R., Luini, A., ... Marubini, E. (2002). Twenty-year follow-up of a randomized study comparing breastconserving surgery with radical mastectomy for early breast cancer. New England Journal of Medicine, 347, 1227-1232.

Vogel, B. A., Helmes, A. W., \& Hasenburg, A. (2008). Concordance between patients' desired and actual decision-making roles in breast cancer care. Psycho-Oncology, 17(2), 182-189. Waller, M., Batt, S. (1995). Advocacy groups for breast cancer patients. CMAJ: Canadian Medical Association Journal, 152(2), 829-833.

Wells, K. J., Lee, J. H., Calcano, E. R., Meade, C D., Rivera, M., Fulp, W. J., \& Roetzheim, R. G. (2012). A cluster randomized trial evaluating the efficacy of patient navigation in improving quality of diagnostic care for patients with breast 
or colorectal cancer abnormalities. Cancer Epidemiology, Biomarkers and Prevention: A Publication of the American Association for Cancer Research, Cosponsored by the American Society of Preventive Oncology, 21(10), 1664-72.

Wengraf, T., (2001). Qualitative Research Interviewing. Thousand Oaks, CA: Sage

Wennberg, J. E. (2002). Unwarranted variations in healthcare delivery: Implications for academic medical centres. British Medical Journal, 325, 961-964, doi: 10.1136/bmj.325.7370.961

Whitney, S. N. (2003). A new model of medical decisions: Exploring the limits of shared decision making. Medical Decision Making, 23(4), 275-280.

Williams, G. C., Cox, E. M., Kouides, R., \& Deci, E. L. (1999). Presenting the facts about smoking to adolescents: The effects of an autonomy supportive style. Archives of Pediatric and Adolescent Medicine, 153(9), 959-964.

Williams, G. C., \& Deci, E. L. (1998). The importance of supporting autonomy in medical education. Annals of Internal Medicine, 129(4), 303-308

Williams, G. C,. Deci, E. L., \& Ryan, R. M. (1998) Building health-care partnerships by supporting autonomy: promoting maintained behavior change and positive health outcomes. In A. L. Suchman, P. Hinton-Walker, \& R. Botelho (Eds.), Partnerships in healthcare: Transforming relational process. (pp. 67-87). Rochester, NY: University of Rochester Press.

Williams, G. C., Frankel, R. M., Campbell, T. L., \& Deci, E. L. (2000). Research on relationship-centered care and healthcare outcomes from the Rochester. Families, Systems \& Health: The Journal of Collaborative Family HealthCare, 18(1), 7990.

Williams, G. C., Freedman, Z. R., \& Deci, E. L, (1998). Supporting autonomy to motivate patients with diabetes for glucose control. Diabetes Care, 21(10), 16441651.

Williams, G. C., Niemiec, C. P., Patrick, H., Ryan, R. M., \& Deci, E. L. (2009). The importance of supporting autonomy and perceived competence in facilitating long-term tobacco abstinence. Annals of Behavioral Medicine: A Publication of the Society of Behavioral Medicine, 37(3), 315-24.

Williams, G. C., Quill, T. E., Deci, E. L., \& Ryan, R. M. (1991). The facts concerning the recent carnival of smoking in Connecticut and elsewhere. Annals of Internal Medicine, 115(1), 59-63

Wilson, A. J., \& Zeitlyn, D. (1994). Speech acts and Stiles: William B. Stiles. (1992). 
Describing Talk: A Taxonomy of Verbal Response Modes. Newberry Park, CA: Sage Publications, $\mathrm{x}+238$ pp. Linguistics and Education, 6(1), 91-98.

Wittmann, E., Beaton, C., Lewis, W. G., Hopper, A. N., Zamawi, F., Jackson, C... Crosby, T. D. L. (2011). Comparison of patients' needs and doctors' perceptions of information requirement related to a diagnosis of oesophageal or gastric cancer. Cancer Care, 20(2), 187-195. 